\title{
Bias-Corrected CMIP5-Derived Single-Forcing Future Wind-Wave Climate Projections toward the End of the Twenty-First Centuryo
}

\author{
GIL LEMOS \\ Instituto Dom Luiz, Faculty of Sciences of the University of Lisbon, Lisbon, Portugal \\ Alvaro Semedo \\ Water Science and Engineering Programme, IHE Delft, Delft, Netherlands, and Instituto Dom Luiz, Faculty of \\ Sciences of the University of Lisbon, Lisbon, Portugal \\ MIKHAIL DOBRYNIN \\ Deutscher Wetterdienst, Hamburg, Germany \\ MELISA MENENDEZ \\ Environmental Hydraulics Institute, Universidad de Cantabria, Santander, Spain \\ Pedro M. A. Miranda \\ Instituto Dom Luiz, Faculty of Sciences of the University of Lisbon, Lisbon, Portugal
}

(Manuscript received 10 December 2019, in final form 6 July 2020)

\begin{abstract}
A quantile-based bias-correction method is applied to a seven-member dynamic ensemble of global wave climate simulations with the aim of reducing the significant wave height $H_{S}$, mean wave period $T_{m}$, and mean wave direction (MWD) biases, in comparison with the ERA5 reanalysis. The corresponding projected changes toward the end of the twenty-first century are assessed. Seven CMIP5 EC-EARTH runs (single forcing) were used to force seven wave model (WAM) realizations (single model), following the RCP8.5 scenario (single scenario). The biases for the 1979-2005 reference period (present climate) are corrected using the empirical Gumbel quantile mapping and empirical quantile mapping methods. The same bias-correction parameters are applied to the $H_{S}, T_{m}$ (and wave energy flux $P_{w}$ ), and MWD future climate projections for the 2081-2100 period. The bias-corrected projected changes show increases in the annual mean $H_{S}(14 \%), T_{m}(6.5 \%)$, and $P_{w}(30 \%)$ in the Southern Hemisphere and decreases in the Northern Hemisphere (mainly in the North Atlantic Ocean) that are more pronounced during local winter. For the upper quantiles, the bias-corrected projected changes are more striking during local summer, up to $120 \%$, for $P_{w}$. After bias correction, the magnitude of the $H_{S}, T_{m}$, and $P_{w}$ original projected changes has generally increased. These results, albeit consistent with recent studies, show the relevance of a quantile-based bias-correction method in the estimation of the future projected changes in swave climate that is able to deal with the misrepresentation of extreme phenomena, especially along the tropical and subtropical latitudes.
\end{abstract}

Supplemental information related to this paper is available at the Journals Online website: https://doi.org/10.1175/JAMC-D-190297.s1.

Corresponding author: Gil Lemos, grlemos@fc.ul.pt

\section{Introduction}

Potential increases of coastal hazards, like inundation or extreme coastal erosion, are among the most disruptive effects of climate change. Therefore, changes in wind-wave climate at the coast are particularly important, especially when combined with sea level rise. Wind waves (henceforth just called waves) are a key driver of coastal hazards and considered one of the main climate drivers impacting the coastal environment, significantly 
contributing to extreme water levels, storm surge effects, and coastal erosion. Increased wave energy at the coast or changes in wave direction (or the combination of both; Morim et al. 2019) are responsible for extreme coastal erosion and changes in coastal geomorphology (Łabuz 2015), particularly in lowland countries and delta areas such as the Mauritius (Bheeroo et al. 2016) or some of the West African countries such as Senegal, Ghana, or Nigeria (Goussard and Ducrocq 2014). Increased wave energy is also responsible for overtopping and coastal flooding and aggravated loads in coastal and offshore structures, decreasing projected life span, with direct economic impacts (IPCC 2014).

Waves are part of the climate system (Cavaleri et al. 1991; Babanin et al. 2012) and play a key role in modulating exchanges of momentum, heat, and mass at the air-sea interface (Sullivan et al. 2008; Högström et al. 2009, 2011; Semedo et al. 2009; Rutgersson et al. 2010). The accurate knowledge of the current wave climate and its trends is a concern for ship and marine infrastructures design standards, emanated from classification societies (Bitner-Gregersen et al. 2015; Bitner-Gregersen and Gramstad 2018). Therefore, besides the monitoring of present wave climate (Young 1999; Young et al. 2011; Aarnes et al. 2015), knowledge of how future changes in climate might impact the future wave climate became an important issue for decision and policy makers in climate change adaptation and mitigation strategies.

Climate change refers to the systematic, long-term changes in the statistics of the climate parameters (such as wave sea-state parameters), sustained over long-term periods (several decades or even longer time periods). From observations (or modeling efforts) it can be assessed how wave climate has been changing in the past. Future wave climate projections, on the other hand, rely on greenhouse gases emission scenarios, set on global climate models (GCMs) used to force dynamic or statistical wave models (Wang et al. 2010). Under the auspices of the Coordinated Ocean Wave Climate projections (COWCLIP) project (Hemer et al. 2010, 2012), supported by the World Climate Research Program-Joint Technical Commission for Oceanography and Marine Meteorology (WCRP-JCOMM), several dynamical and statistical global wave climate projections have recently been produced. The first studies were based on phase 3 of the Coupled Model Intercomparison Project (CMIP3) GCM climate simulations for the forcing (e.g., Mori et al. 2010; Hemer et al. 2013b; Semedo et al. 2013; Fan et al. 2013) of wave models, further leading to an "opportunity" wave climate ensemble (Hemer et al. 2013a): the COWCLIP-1 ensemble. The use of ensembles has been widely accepted in recent climate studies, with the goal of reducing the uncertainties arising from the GCM's internal variability (Hawkins and Sutton 2009; Knutti and
Sedláček 2013; Rauser et al. 2015). Dedicated dynamic and statistical ensembles of wave climate simulations, using wind or mean sea level pressure fields, and sea ice cover (SIC), from phase 5 of CMIP (CMIP5) GCMs as forcing, have also been recently pursued (e.g., Hemer and Trenham 2016; Aarnes et al. 2017; Camus et al. 2017; Casas-Prat et al. 2018). These wave climate ensembles relied on a multiforcing strategy, that is, different GCMs were used to force a single statistical or dynamical wave model. In this study, however, a different approach is pursued in which a seven-member single-GCM forced dynamic wave climate ensemble is used to study the effect of climate change on the late-twenty-first-century global wave climate. Since it uses the same GCM (EC-EARTH), with the same radiative forcing (RCP8.5) and the same wave model (WAM), the ensemble is named as a "singleforcing, single-(wave)-model, single scenario" ensemble, as in Semedo et al. (2018) and Lemos et al. (2019). This ensemble was built with the goal of reducing the variability that is inherent to a multiforcing GCM approach (for the same wave model), such as in Hemer and Trenham (2016).

Standard future climate studies rely on the comparison between the present (historical) climate (recent past) and the future climate projections. The climate change impact in the future is then assessed by the differences between the historical and the future climates. Projected changes in the future should then be seen in the context adopted models' ability to reproduce the historical climate. The understanding of how well the GCM or a wave model represents the climatological mean state and temporal variability of the historical climate is a key step. GCM atmospheric simulations often exhibit biases resulting from simplified physics or parameterization within the models (Rocheta et al. 2017), which can cascade, increasing the uncertainty, by forcing wave models offline. To correct these systematic errors, and to improve the present climate simulations' agreement with observations or reanalyses/hindcasts, the implementation of bias-correction (BC) procedures has become common practice in recent climate studies, on parameters such as temperature (Applequist 2012), winds (Hemer et al. 2012), and precipitation (Terink et al. 2009). To the extent of our knowledge, the application of BC techniques to dynamic global wave climate projections is still limited in the scientific literature (Lemos et al. 2020).

$\mathrm{BC}$ methods range in complexity, from the simplest one, the "delta" method (Hay et al. 2000), to more elaborated ones, as the quantile mapping (Déqué 2007; Boé et al. 2007; Amengual et al. 2012) or linear/nonlinear regression methods (e.g., Hay and Clark 2003; von Storch and Zwiers 1999; Mínguez et al. 2011). The BC strategy has embedded the fundamental assumption that the bias behavior of the climate simulation, assessed in the historic period, does not change in time and is the same in the future climate period 
(Haerter et al. 2011). For that matter, in this study, the present (1979-2005) and future (2081-2100) wave climate simulations' time slices' biases are corrected using the empirical Gumbel quantile mapping (EGQM) and empirical quantile mapping (EQM) methods (Dequé 2007; Amengual et al. 2012), having the ERA5 reanalysis (Copernicus Climate Change Service 2017; Hersbach et al. 2020) as the historical reference. The goal of the present study is to assess the impact of a warmer climate on the future global significant wave height $H_{S}$, mean wave period $T_{m}$, wave energy flux $P_{w}$, and mean wave direction (MWD) fields, after bias correction, using the WAM EC-EARTH single-forcing, singlemodel and single-scenario wave climate ensemble and two of the bias-correction methods defined in Lemos et al. (2020).

The remainder of the paper is structured as follows: in section 2, the WAM EC-EARTH ensemble and the ERA5 reanalysis, as well as the EGQM and EQM BC methods, are presented. In section 3 , the bias-correction performance is analyzed and the results from the bias-corrected future wave climate projections are presented. Results are discussed and summarized in section 4 .

\section{Models, data, and methods}

\section{a. The ERA5 reanalysis}

The ERA5 is a global ECMWF reanalysis, produced using the Integrated Forecast System cycle CY41R2 release, covering the period from 1979 to 2018, being extended in almost real time. The ERA5 (similar to its ERA-Interim reanalysis predecessor; Dee et al. 2011) was produced using an improved data assimilation technique (4D-Var scheme). The horizontal resolution of the atmospheric model in ERA5 is about $30 \mathrm{~km}\left(\sim 0.25^{\circ} \times 0.25^{\circ}\right)$, and the wave parameters have a resolution of about $40 \mathrm{~km}\left(\sim 0.36^{\circ} \times 0.36^{\circ}\right)$. The time resolution is $1 \mathrm{~h}$. The WAM model in ERA5 was set with a spectral resolution of 30 logarithmically spaced frequency bins (from 0.03453 to $0.5478 \mathrm{~Hz}$ ), and 24 directional bins of $15^{\circ}$. The bottom topography in ERA5 is based on the ETOPO2 (NGDC 2006) dataset. Additional details about the ERA5 reanalysis can be found in Copernicus Climate Change Service (2017) and in Hersbach et al. (2020).

Preliminary results from the ERA5 wave reanalysis performance evaluation showed that it tends to slightly underestimate the $H_{S}$ Bidlot et al. (2019), when compared with an extensive dataset of in situ observations, altimetry measurements, and previous reanalyzes/hindcasts. It was concluded, nevertheless, that the ERA5 performs better than previous wave products in several areas of the global ocean (J. Bidlot 2019, personal communication), which provides the necessary confidence in the ability of the ERA5 to accurately represent the global wave climate, in this study. Here, the global $H_{S}, T_{m}$, and MWD parameters from the ERA5 dataset, at a 6-hourly time resolution and interpolated to a $1^{\circ} \times 1^{\circ}$ horizontal resolution (to match the wave climate simulations) were used to train the BC method, from 1 January 1979 to 31 December 2005.

\section{b. The single-forcing, single-model, single-scenario wave climate ensemble}

Seven EC-EARTH climate simulation runs were used to force the third-generation wave model WAM cycle 4.5.3 with $10-\mathrm{m}$ wind speed $U_{10}$ and SIC fields, producing the seven wave ensemble members. Each EC-EARTH integration started in 1850 , being differentiated by the initial conditions, which are snapshots taken from the long preindustrial control simulation for CMIP5, 25 years apart. The WAM global domain was set to a regular global latitude-longitude grid (from $78^{\circ} \mathrm{N}$ to $78^{\circ} \mathrm{S}$ ) with a fixed horizontal spatial grid size of $1^{\circ} \times 1^{\circ}$, a spectral resolution of 25 logarithmically spaced frequency bins (from 0.041 to $0.411 \mathrm{~Hz}$ ) and directional bins of $15^{\circ}$, and a 6-hourly time resolution. The 1-min $\left(\sim 0.0168^{\circ}\right)$ ETOPO1 data (Amante and Eakins 2009) have been used for bottom topography.

The single-forcing, single-model, single-scenario wave climate ensemble performance skills used here have been extensively evaluated against in situ wave observations, a wave reanalysis (ERA-Interim; Dee et al. 2011), and a wave hindcast (CFSR; Saha et al. 2010), as shown in Semedo et al. (2018), and against remote sensing altimetry observations (Stopa et al. 2019). Further details on the ensemble design and performance skills, as well on the EC-EARTH and WAM setups, can be seen in Semedo et al. (2018).

The WAM EC-EARTH wave climate simulations were divided into three time slices: a present climate historic time slice from 1979 to 2005 (the overlapping period with ERA5), henceforth named as PC20, used to compute the bias corrections, a 20-yr run time slice from 1986 to 2005, henceforth named as PC20-C, and a late-twenty-firstcentury future time slice, from 2081 to 2100 (also 20 years), henceforth named as FC21. The seven wave climate ensemble members were named for convenience from PC20-1 to PC20-7, from PC20-C-1 to PC20-C-7, and from FC21-1 to FC21-7, for the present, control run, and future periods, respectively. The wave climate ensemble was built considering unweighted means of the individual members. The wave climate changes are assessed by comparison between the PC20-C and the FC21 time slices.

In the high latitudes, SIC was dealt with following one of the procedures proposed by Tuomi et al. (2011), in which only grid points with $30 \%$ or less ice concentration along the time series were treated as open water.

\section{c. The EGQM and the EQM bias-correction methods}

The EGQM method consists of calibrating a simulated empirical cumulative distribution function (ECDF; Wilks 1995), by adding a correction term to each 
individual (preselected) quantile. The quantiles where this correction term is applied are defined by a standard Gumbel distribution (SGD; Gumbel 1935), with a better representation of the upper tail of the distribution. This method was used to correct the $H_{S}$ and $T_{m}$ parameters, during PC20. For the application of the EGQM method, a set of $n_{q}=20$ quantiles was selected, following an SGD, between the 1st quantile and the 99.999th quantile, where 11 of the 20 selected quantiles are above the 99th percentile, focusing on the correction of the extreme values, where higher biases are usually found.

The correction term is calculated as the difference between the inverse ECDFs of ERA5 $\left(\mathrm{ECDF}^{\mathrm{ERA} 5^{-1}}\right)$ and $\mathrm{PC} 20\left(\mathrm{ECDF}^{\mathrm{PC} 20^{-1}}\right)$, at each selected quantile, and is applied at every $1^{\circ} \times 1^{\circ}$ grid point of the PC20 global fields:

$$
\begin{aligned}
X\left(q_{i}\right) & =\operatorname{ECDF}^{\mathrm{ERA}^{-1}}\left(q_{i}\right)-\operatorname{ECDF}^{\mathrm{PC}^{2} 0^{-1}}\left(q_{i}\right), \\
i & =1, \ldots, n_{q}, \quad \text { and } \\
\operatorname{PC} 20^{C}\left(q_{i}\right) & =\operatorname{PC} 20\left(q_{i}\right)+X\left(q_{i}\right), \quad i=1, \ldots, n_{q},
\end{aligned}
$$

where PC20 is the original wave parameter and $\mathrm{PC} 20^{C}$ is the bias-corrected one, at each selected quantile. The correction terms are linearly interpolated between the selected quantiles. All data outside the defined quantile range are extrapolated using the same correction terms found for the first and last selected quantiles.

A simplified version of the EGQM, the EQM, method was used to correct the PC20 MWD. Both the ERA5 and the original PC20 MWDs were transformed into zonal $(u)$ and meridional $(v)$ components, each corrected individually. For the EQM method, a linearly spaced set of quantiles was chosen, from the 1 st to the 99th quantile $\left(n_{q}=99\right)$. The implementation then followed the EGQM method, by solving Eqs. (1) and (2), at every $1^{\circ} \times 1^{\circ}$ grid point. The bias-corrected $u$ and $v$ components were finally used to reconstruct the MWD parameter.

\section{d. General method for bias-correction evaluation}

The BC terms were computed for each ensemble members' $H_{S}, T_{m}$, and MWD global fields, for the PC20 (1979-2005) time slice, with ERA5 as the "ground truth." These correction terms were further applied to the wave climate projections in the FC21 (2081-2100) time slice, assuming that the original bias properties are propagated into the future projections.

The BC terms were computed using the EGQM $\left(H_{S}\right.$ and $\left.T_{m}\right)$ and EQM (MWD) methods, for each grid point [as in Lemos et al. (2020)]. After correction, the ensemble was rebuilt considering the uniformly weighted mean of the individual members. The $T_{m}$ used here is defined as the ratio between the first-negative and the zeroth moments, as $T_{m}=m_{-1} / m_{0}$. Results from the bias-corrected wave energy flux $\left(P_{w}\right)$ projections were also analyzed, considering the extreme events (mean above the 99th quantile), where $P_{w}=\left(\rho g^{2} / 64 \pi\right) T_{m} H_{S}^{2}$ (Holthuijsen 2008).

The ability of the EGQM and EQM methods to correct the PC20 members is evaluated for the global ocean, and at 13 different subareas, allowing a regional assessment of the bias-correction performance. The subareas were chosen according to Alves (2006) and are detailed in the online supplemental material (Table SM1 and Fig. SM1). The evaluation is carried out at each grid point, using the bias [Eq. (3)], the PDF score [Perkins et al. 2007; Boberg et al. 2009; Brands et al. 2011; Eq. (4)], the distribution added value [DAV; Soares and Cardoso 2018; Eq. (5)], and the Yule-Kendall skewness measure [YK; Ferro et al. 2005; Eq. (6)] metrics, defined respectively as

$$
\begin{aligned}
& \text { bias }=\frac{1}{N} \sum_{i=1}^{N} \mathrm{PC}_{i}-\frac{1}{N} \sum_{i=1}^{N} \mathrm{ERA}_{i}, \\
& \text { PDF Score }=\int \min \left(\mathrm{PDF}_{\mathrm{PC} 20}, \mathrm{PDF}_{\mathrm{ERA} 5}\right) \text {, }
\end{aligned}
$$

where $i$ is the index of the data at each grid point; $N$ is the length of the time series; ERA5 refers to the reference ERA5 data; PC20 refers to each of the PC20 members (from PC20-1 to PC20-7); $C$ and $O$ are the 

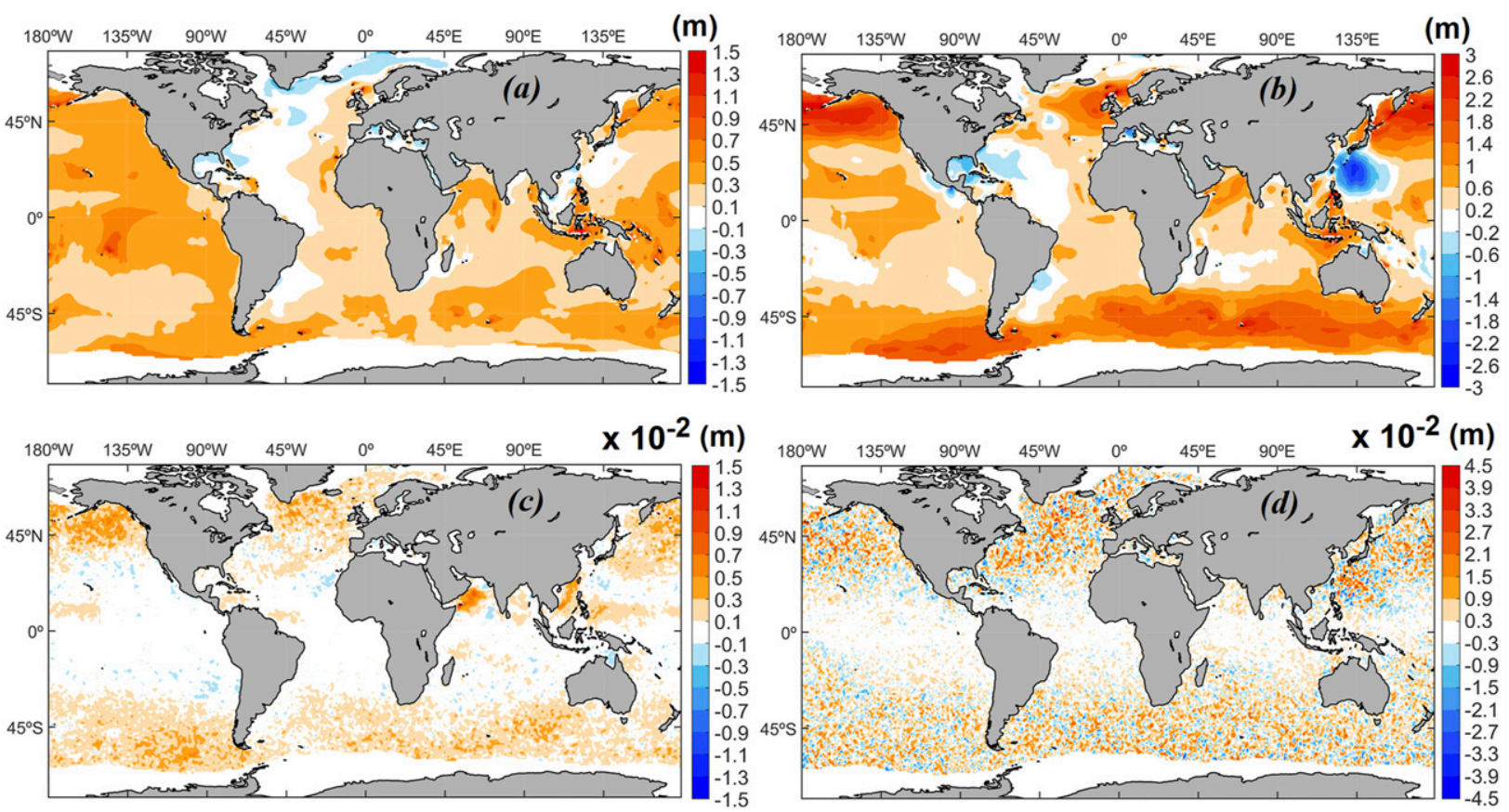

FIG. 1. Original PC20 $H_{S}$ bias (m) relative to ERA5 for (a) the annual mean $H_{S}(\mathrm{~m})$ and (b) the extreme mean (mean for values higher than the 99th quantile) $H_{S}(\mathrm{~m})$, and (c),(d) the corresponding bias-corrected fields, using the EGQM method. The color scales vary among the panels.

bias-corrected and original datasets; and P95, P50, and $P 5$ correspond to the 95th, 50th, and 5th quantiles, respectively.

While the PDF score provides a measure of the common area between the empirical PDFs of each of the seven PC20 ensemble members and ERA5 ranging from 0 (no overlap) to 1 (perfect overlap), the DAV relates two PDF scores (the original and bias-corrected ones) by normalizing their difference (bias corrected minus originals, divided by the originals). Positive or negative DAVs are related to an increase or decrease, respectively, in the common area between PDFs after applying the BC.

The YK measures are used to estimate the skewness of the PC20 distributions, in comparison with those of ERA5. The skewnesses are computed using the relative positions of the 95th and 5th quantiles with respect to the median (50th quantile), resulting in a positive value for rightskewed curves and a negative value for left-skewed curves.

\section{Results}

\section{a. Performance of bias correction}

The PC20 original annual mean and extreme mean (mean above the 99th quantile) $H_{S}$ biases, computed using Eq. (3), are presented in Fig. 1, as well as the respective corrected biases. Global and regional quantile-quantile (Q-Q) plots are shown in Fig. SM2 of the online supplemental material. The original PC20 overestimates the mean $H_{S}$ in most of the global ocean, relative to ERA5 (Fig. 1a and supplemental Fig. SM2a), particularly in the Pacific Ocean and in the mid-to-high latitudes of the Southern Hemisphere, between 0.1 and $0.5 \mathrm{~m}$ (Figs. SM2d-f; Table 1). Locally higher biases are visible near some archipelagos (e.g., Polynesia, Micronesia, Maldives, Hawaii, and the Aleutian Islands). These differences, however, occur potentially due to unresolved subgrid-scale bathymetry in the PC20 WAM setup (Semedo et al. 2018), taken into account in ERA5. The original PC20 agreement with ERA5 can be considered as good in the Atlantic basin, but biases up to $0.5 \mathrm{~m}$ are still visible in Fig. 1a. The original biases for the extreme mean $H_{S}$ also show a consistent PC20 overestimation along the extratropical latitudes of both hemispheres (Fig. 1b and supplemental Figs. SM2b-f), generally below $2.2 \mathrm{~m}$, but up to $2.6 \mathrm{~m}$ in the North Pacific subbasin (Fig. SM2c). A possible misrepresentation of tropical cyclones in PC20, compared to ERA5 (which potentially better simulates tropical cyclones due to its higher temporal and spatial resolution), is also noticeable, in the tropical North Atlantic (e.g., Gulf of Mexico and Caribbean Sea) and Pacific (e.g., Philippines Sea) (Fig. SM2j). The original biases there show a PC20 underestimation of the extreme $H_{S}$, locally reaching 1 and $3 \mathrm{~m}$ in the North Atlantic and North Pacific, respectively. After the bias correction has been applied, improvements 
TABLE 1. PC20 original (OR) and corrected (BC) biases for the annual mean $H_{S}, T_{m}$, and MWD wave parameters. Here, "key p." means "key point," roughly in the center of each area because it is not possible to average MWD over the entire area. The key points are shown in Fig. SM4; "N/D" means "no data available."

\begin{tabular}{lcccccc}
\hline \hline Area & $H_{S}$ OR $(\mathrm{m})$ & $H_{S} \mathrm{BC}(\mathrm{m})$ & $T_{m}$ OR $(\mathrm{s})$ & $T_{m} \mathrm{BC}(\mathrm{s})$ & MWD OR $\left(\mathrm{key} \mathrm{p.)}\left(^{\circ}\right)\right.$ & $\mathrm{MWD}$ BC $\left(\mathrm{key}\right.$ p.) $\left(^{\circ}\right)$ \\
\hline Global & 0.25 & $8.81 \times 10^{-4}$ & 1.06 & $4.68 \times 10^{-4}$ & $\mathrm{~N} / \mathrm{D}$ & $\mathrm{N} / \mathrm{D}$ \\
ETNA & -0.02 & $1.20 \times 10^{-3}$ & 0.42 & $2.10 \times 10^{-3}$ & -2.51 & $3.50 \times 10^{-3}$ \\
ETNP & 0.30 & $2.10 \times 10^{-3}$ & 1.22 & $7.00 \times 10^{-3}$ & -1.43 & $-2.90 \times 10^{-3}$ \\
ETSA & 0.26 & $1.00 \times 10^{-3}$ & 0.89 & $3.26 \times 10^{-4}$ & -21 & $-2.80 \times 10^{-3}$ \\
ETSP & 0.32 & $1.40 \times 10^{-3}$ & 1.09 & $2.65 \times 10^{-4}$ & 4.08 & $6.40 \times 10^{-3}$ \\
ETSI & 0.30 & $1.30 \times 10^{-3}$ & 0.92 & $9.84 \times 10^{-4}$ & 1.30 & $-4.50 \times 10^{-3}$ \\
TNAO & 0.08 & $3.56 \times 10^{-4}$ & 0.74 & $5.90 \times 10^{-4}$ & 0.66 & -0.03 \\
TSAO & 0.18 & $1.06 \times 10^{-4}$ & 1.03 & $-6.59 \times 10^{-4}$ & 1.33 & -0.04 \\
TENP & 0.33 & $1.02 \times 10^{-4}$ & 1.59 & $-1.40 \times 10^{-3}$ & 29.3 & $-3.80 \times 10^{-3}$ \\
TWNP & 0.19 & $9.72 \times 10^{-4}$ & 1.23 & $2.50 \times 10^{-3}$ & 10.9 & -0.01 \\
TESP & 0.34 & $-1.51 \times 10^{-4}$ & 1.33 & $-2.20 \times 10^{-3}$ & 24.8 & $-3.00 \times 10^{-3}$ \\
TWSP & 0.43 & $-9.33 \times 10^{-5}$ & 1.75 & $-7.10 \times 10^{-4}$ & 10.6 & $-2.5 \times 10^{-3}$ \\
TNIO & 0.19 & $7.77 \times 10^{-4}$ & 1.39 & $1.20 \times 10^{-3}$ & 5.22 & -0.01 \\
TSIO & 0.23 & $1.92 \times 10^{-4}$ & 1.24 & $-1.30 \times 10^{-3}$ & 16.6 & -0.07 \\
\hline
\end{tabular}

of two-three orders of magnitude are visible for the annual mean and extreme mean (mean above the 99th quantile) $H_{S}$ biases. The annual mean $H_{S}$ biases virtually disappear, with values below $0.01 \mathrm{~m}$. The corrected biases are not zero, however, because of the linear nature of the correction parameters' interpolation, between each of the predefined quantiles (only nine of them are below the 99th). This also allows part of the uncertainty to be kept.

Figure 2 is similar to Fig. 1, but for $T_{m}$. Global and regional Q-Q plots are shown in Fig. SM3 of the online supplemental material. Similarly to $H_{S}$, the original PC20 mean and extreme $T_{m}$ values are mostly overestimated across the global ocean, relative to ERA5 (also visible in Fig. SM3a and Table 1). However, slightly higher biases (above $1 \mathrm{~s}$ ) are visible along the tropical latitudes of both hemispheres, in the so-called swell pools (Semedo 2010). Higher biases in the intertropical latitudes can also be seen in Figs. SM3i (TENP), SM3j (TWNP), SM3k (TESP), SM3l (TWSP), SM3m (TNIO), and SM3n (TSIO) (see Fig. SM1 for regional areas and acronym definitions). After correction, the biases of the annual mean and extreme mean $T_{m}$ are effectively reduced, globally, with values generally bellow 0.01 and $0.04 \mathrm{~s}$, respectively (Figs. 2c,d),
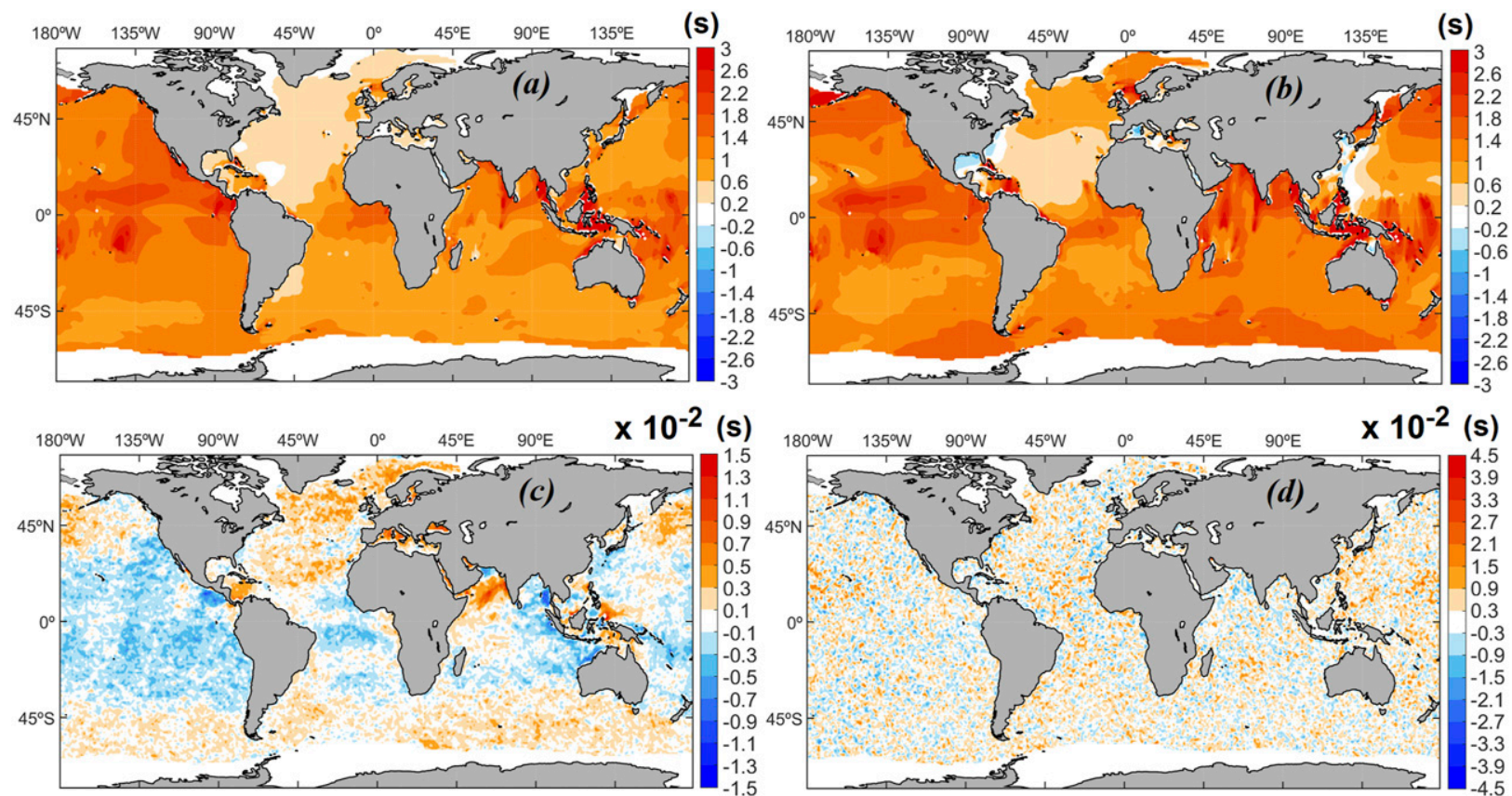

FIG. 2. As in Fig. 1, but for $T_{m}$ (s). The color scales vary among the panels. 

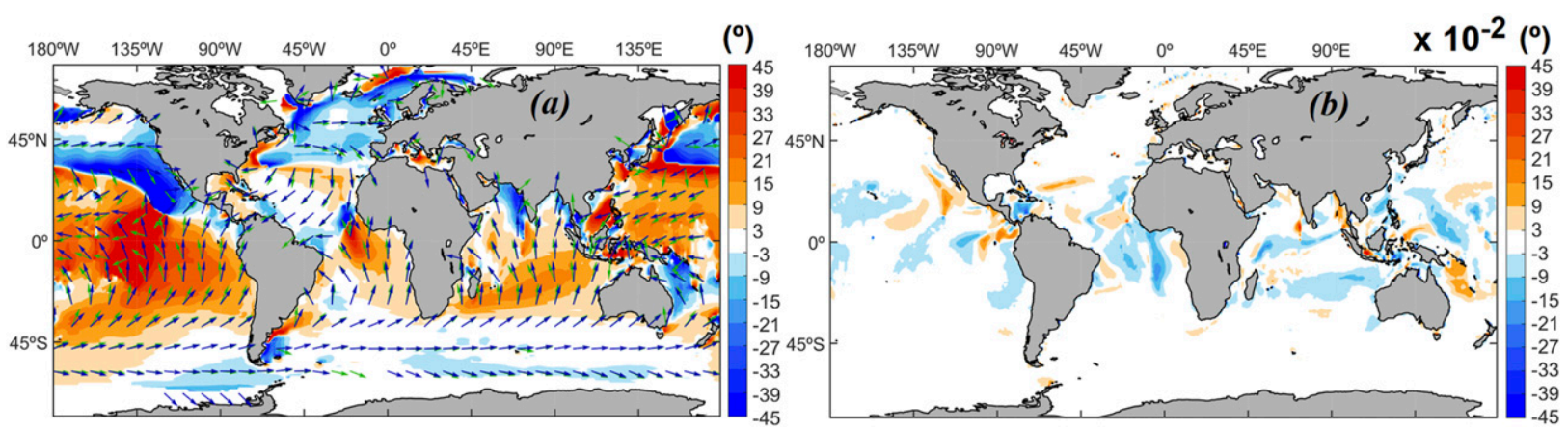

FIG. 3. (a) Original PC20 annual mean MWD bias ( ${ }^{\circ}$; color shades) relative to the ERA5 reanalysis (blue arrows show the original PC20 MWD, and green arrows show the ERA5 MWD). (b) Bias-corrected PC20 annual mean MWD bias $\left({ }^{\circ}\right)$, using the EQM method, relative to the ERA5 reanalysis.

showing improvements that can exceed two orders of magnitude.

Figure 3 shows the PC20 uncorrected annual mean MWD biases, overlapped with the PC20 (blue) and ERA5 (green) MWD arrows. While negative (counterclockwise) biases are mostly visible in the extratropical latitudes of both hemispheres, associated with a more western MWD component along the storm belts, positive (clockwise) biases prevail along the tropical latitudes. These positive biases are associated with an enhanced southerly MWD component in PC20, most probably associated with intensified swell propagation from the Southern Ocean (as supported by Figs. 1 and 2 and supplemental Figs. SM2 and SM3). While the highest original biases are visible mainly along the intertropical latitudes, and Northern Hemisphere, the lowest values are present in the extratropical latitudes of the Southern Hemisphere (Southern Ocean), being associated with higher and lower MWD intra-annual variability, respectively. The ERA5, and original and bias-corrected PC20 MWD relative frequencies (\%), considering $5^{\circ}$ bins, at centered key locations inside each of 13 selected areas, are shown in Fig. SM4 of the online supplemental material. The higher (and clockwise) original biases are visible along the tropical latitudes of the Pacific and Indian oceans, in Figs. SM4h (TENP), SM4i (TWNP), SM4j (TESP), SM4k (TWSP), SM4l (TNIO), and SM4m (TSIO) and in Table 1. After the correction of the directional biases, very low values are visible in most of the global ocean (Fig. 3b and supplemental Fig. SM4), showing improvements of two orders of magnitude along the tropical and subtropical latitudes, and above three orders of magnitude along the extratropical latitudes of both hemispheres (Table 1).

The improvements visible for the $H_{S}$ (Figs. 1c,d), $T_{m}$ (Figs. 2c,d), and MWD (Fig. 3b) are, however, responsible for constraining the original PC20 intermember uncertainty, since all the ensemble members are corrected using the same reference dataset (ERA5 reanalysis). For the $H_{S}$ and $T_{m}$, the high sensitivity to the reference dataset is especially relevant at the extremes, since 11 of the 20 predefined quantiles for the EGQM method are above the 99th. Therefore, the results in section $3 \mathrm{~b}$ should be interpreted considering this limitation, taking also into account that the ERA5 reanalysis tends to slightly underestimate the mean and extreme $H_{S}$ (Bidlot et al. 2019), when compared with in situ observations, altimetry data and previous reanalyses/hindcasts.

The PC20 ability to represent $H_{S}$ and $T_{m}$ intra-annual variability was also evaluated. This comparison was done for the global ocean and separately for the 13 selected areas. The $H_{S}$ intra-annual variabilities (daily averaged) for the original and bias-corrected PC20, as well as for the reference ERA5, are displayed in Fig. 4. The widespread original PC20 $H_{S}$ daily mean overestimation across the global ocean, between around 0.2 and $0.4 \mathrm{~m}$ throughout the year, peaking in the late months, is visible in Fig. 4a. The higher Northern Hemisphere intra-annual variability is to blame here, adding higher original biases during the boreal winter (Figs. $4 \mathrm{~b}, \mathrm{c}$ ) to the relatively stable Southern Hemisphere original biases (Figs. 4d-f). A good agreement between the original PC20 $H_{S}$ and the ERA5 $H_{S}$ is visible for the ETNA area (Fig. 4b, also visible in Fig. 1a); however, for tropical areas such as TENP and TWSP, the agreement is worse (Figs. 4i,l), with daily mean overestimations punctually exceeding $0.5 \mathrm{~m}$. After the correction of the biases, the agreement of both the global and regional $H_{S}$ daily means with ERA5 increased. The differences between the bias-corrected and ERA5 $H_{S}$ daily means are generally below $0.1 \mathrm{~m}$.

Figure 5 is similar to Fig. 4 , but for $T_{m}$. The original PC20 $T_{m}$ overestimation is present for both the global ocean (Fig. 5a) and for all the regional areas (Fig. 5b-n), similar to $H_{S}$ (Fig. 4). Higher original daily mean biases are visible in the TWSP area, reaching $2 \mathrm{~s}$ during the 

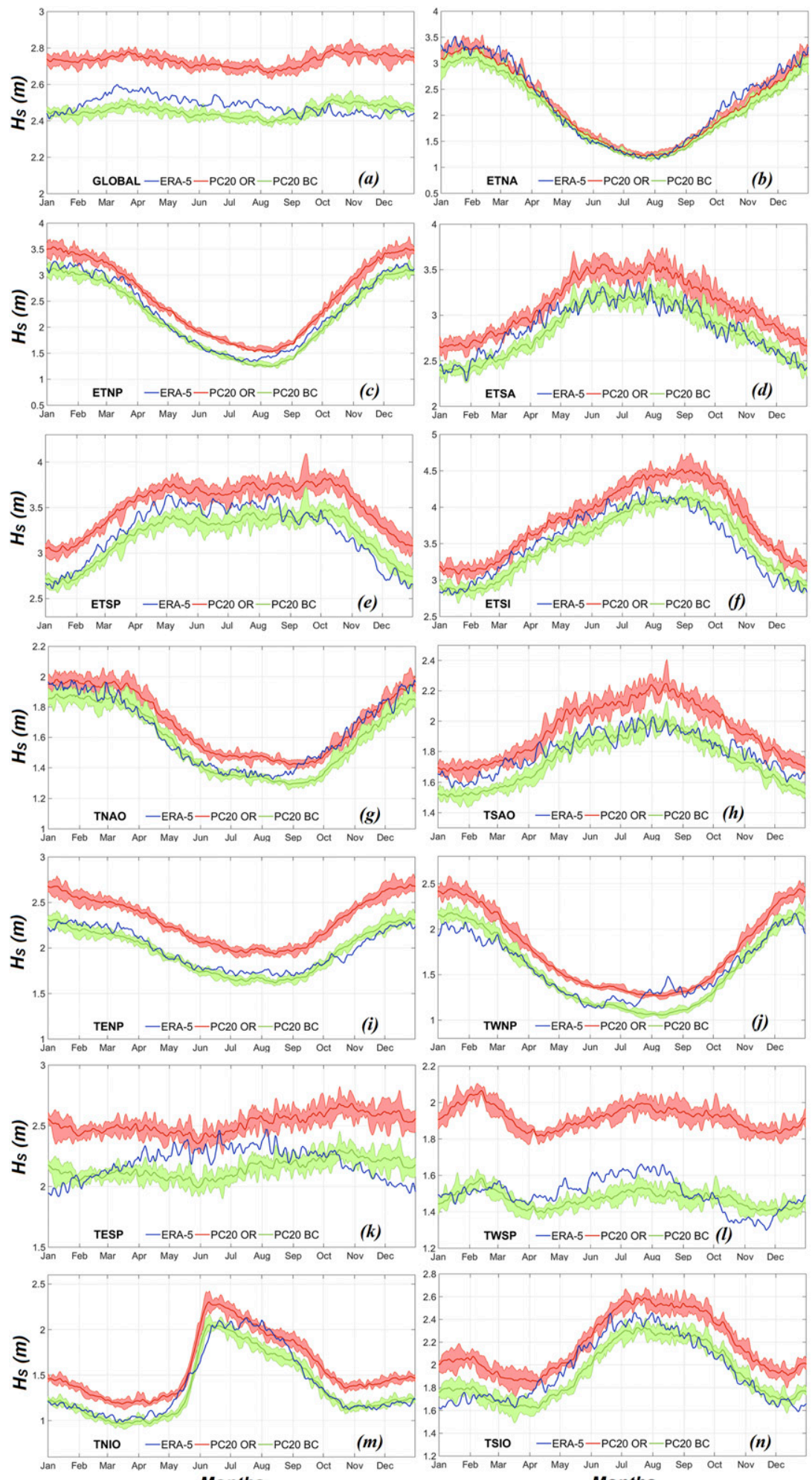

FIG. 4. The $H_{S}$ intra-annual variability (daily means) from the original (red line) and biascorrected (green line) PC20 and from ERA5 (blue line) for the following areas: (a) global, (b) ETNA, (c) ETNP, (d) ETSA, (e) ETSP, (f) ETSI, (g) TNAO, (h) TSAO, (i) TENP, (j) TWNP, (k) TESP, (l) TWSP, (m) TNIO, and (n) TSIO. The red and green bands represent ensemble members spread for the original and bias-corrected PC20, respectively. The magnitude of the vertical axes varies among the panels. 

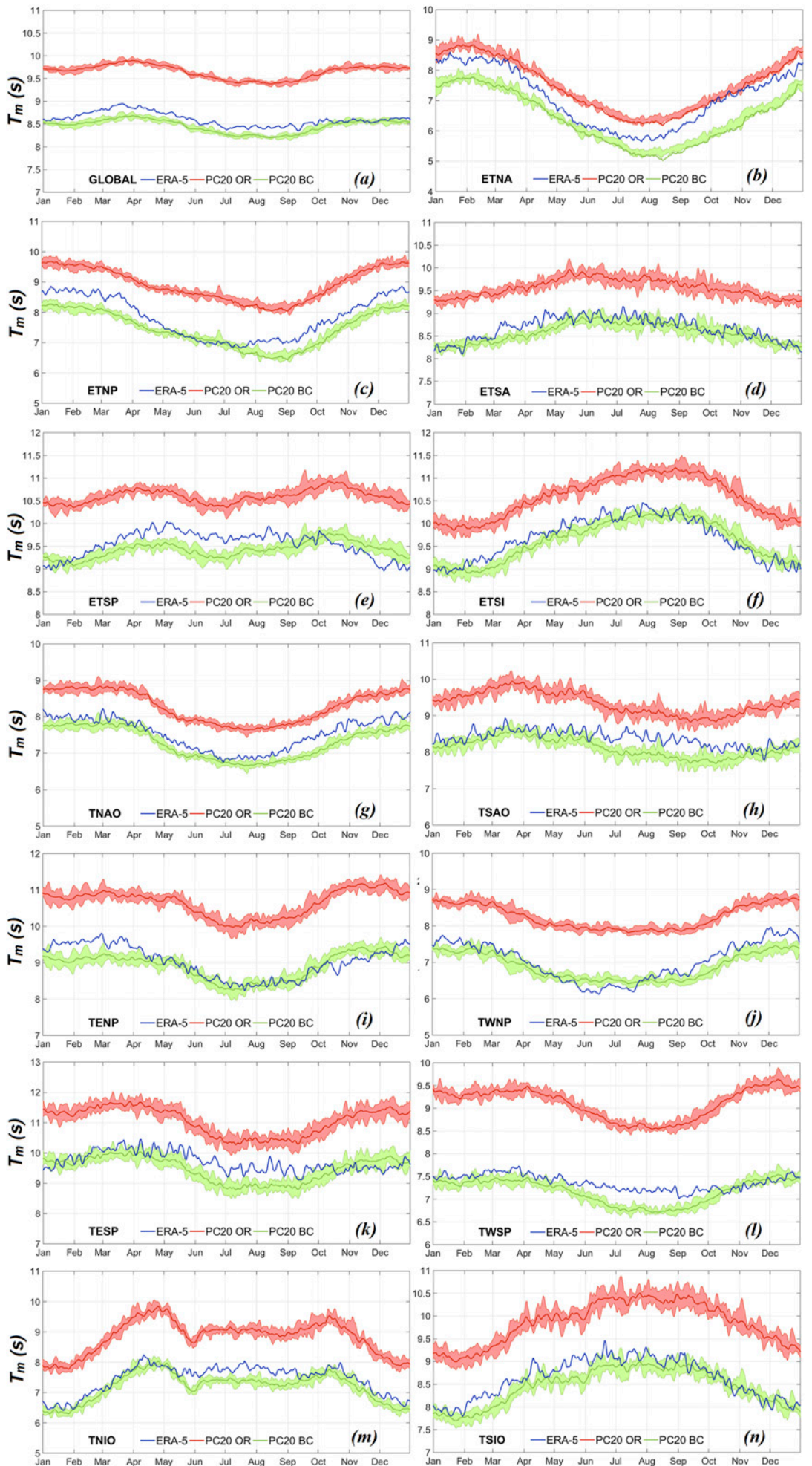

Months

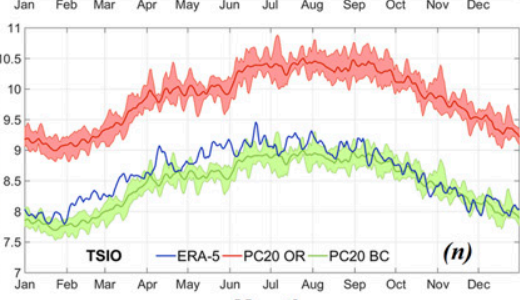

Months

FIG. 5. As in Fig. 4, but for $T_{m}$ (s). The magnitude of the vertical axes varies among the panels. 

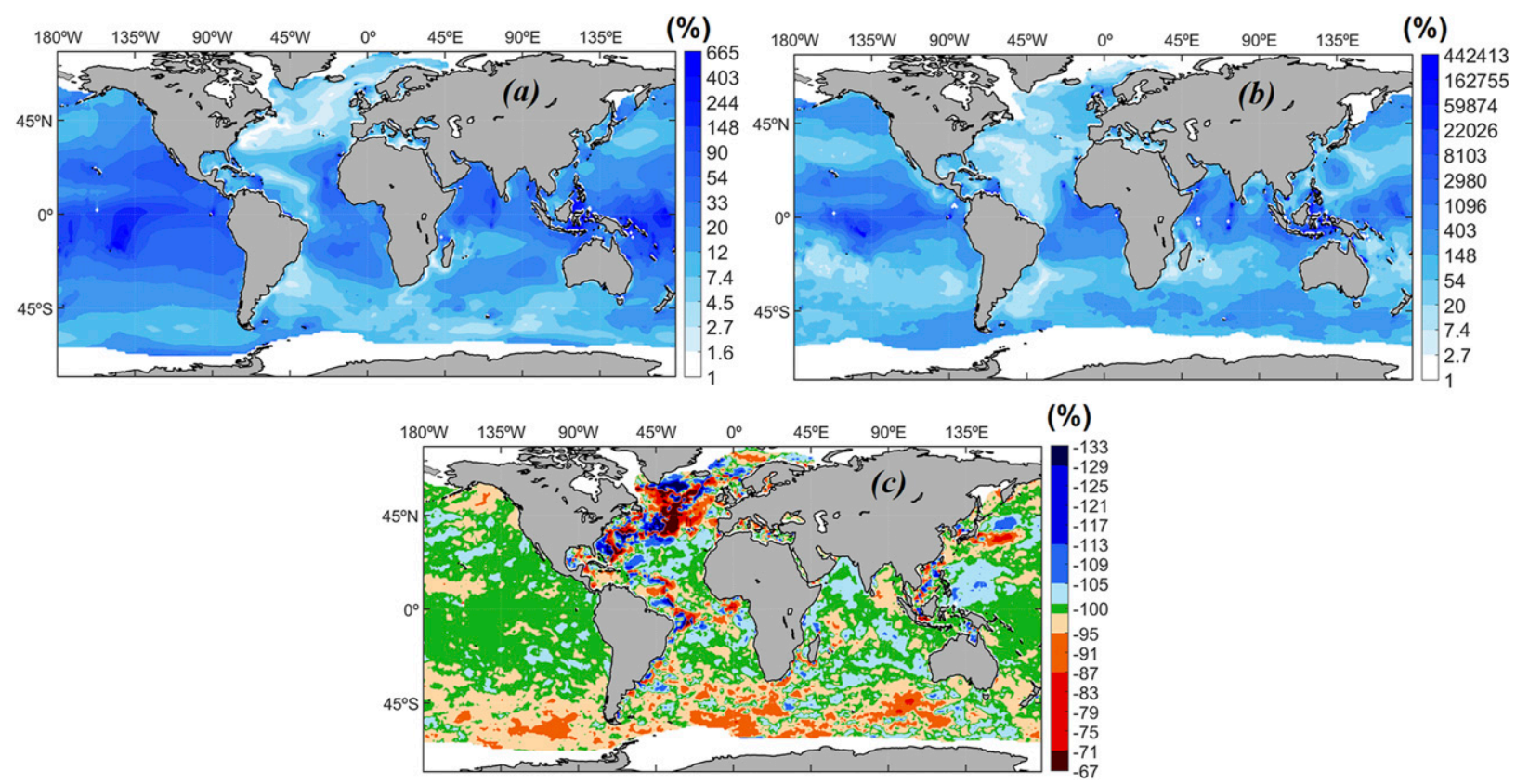

FIG. 6. DAV (\%) between the bias-corrected and original PC20 (a) $H_{S}$ and (b) $H_{S}$ for values higher than the 99th quantile. Also shown are (c) normalized differences (\%) between the bias-corrected and original YK skewness measure, relative to the ERA5 reanalysis. The color scales vary among the panels. The normalized differences are defined as bias-corrected minus original, normalized by the original.

early and late months of the year (austral winter). For the ETNA area, a good agreement between the original and the ERA5 $T_{m}$ daily means is visible, with biases below $0.8 \mathrm{~s}$. After the biases have been corrected, the agreement improved in all areas. The differences between the bias-corrected and ERA5 $H_{S}$ daily means are generally below $0.5 \mathrm{~s}$.

In both Figs. 4 and 5 (for $H_{S}$ and $T_{m}$ ), agreement with ERA5 improved after bias correction. However, biases in the daily means are still visible, since the EGQM method only acted by correcting specific quantiles in each time series, interpolating linearly between them. Therefore, the original intra-annual variability, as well as the daily mean intermember uncertainty (spread), is mostly conserved after bias correction. Despite the virtually inexistent annual mean bias (considering the entire time series), low biases are still present when smaller time scales are considered (like daily means).

The DAVs from the comparison between the $H_{S}$ PDF scores [Eq. (5)], considering the entire distribution and the $H_{S}$ values above the 99th quantile, as well as the normalized differences between the bias-corrected and original PC20 $H_{S}$ YK, relative to ERA5, are displayed in Fig. 6. While the highest uncorrected $H_{S}$ PDF scores are present along the extratropical latitudes of both hemispheres, generally above 0.7 (not shown), the lowest ones are found in the tropical and subtropical latitudes (very close to zero for the $H_{S}$ values above the 99th quantile). The potential misrepresentation of local phenomena by PC20 can explain the higher mismatch between the PC20 and the ERA5 PDFs, due to the higher $H_{S}$ interannual variability in these areas, owing to the presence of tropical cyclones. As a matter of fact, it is in the tropical and subtropical latitudes that both DAVs for the entire and upper tail of the distribution assume the highest values, corresponding to the greatest increases in the PDF scores after bias correction. While the DAVs in Fig. 6a show increases in the original PDF scores of up to one order of magnitude, in Fig. 6b, these can locally exceed three orders of magnitude. The smallest increases in the original PDF scores are present in the Atlantic Ocean (mainly along the North Atlantic), where the original agreement between PC20 and the ERA5 reanalysis was already relatively good (Figs. $1 \mathrm{a}, \mathrm{b}$ and $4 \mathrm{~b}$ ).

Considering the normalized differences between the bias-corrected and original PC20 $H_{S}$ YK measures, present in Fig. 6c, it is clear that after the correction of the biases, the YK dropped across the global ocean, to values close to zero (green areas; reduction between $-99 \%$ and $-101 \%)$. A total agreement between the PC20 and ERA5 skewness, after bias correction, would result in a (virtual) YK value of 0 and normalized difference value of $-100 \%$. However, a change in the YK signal, after bias correction, yields values below $-100 \%$. In the higher latitudes of the Southern Hemisphere and in the North Atlantic subbasin, the stronger YK normalized differences 

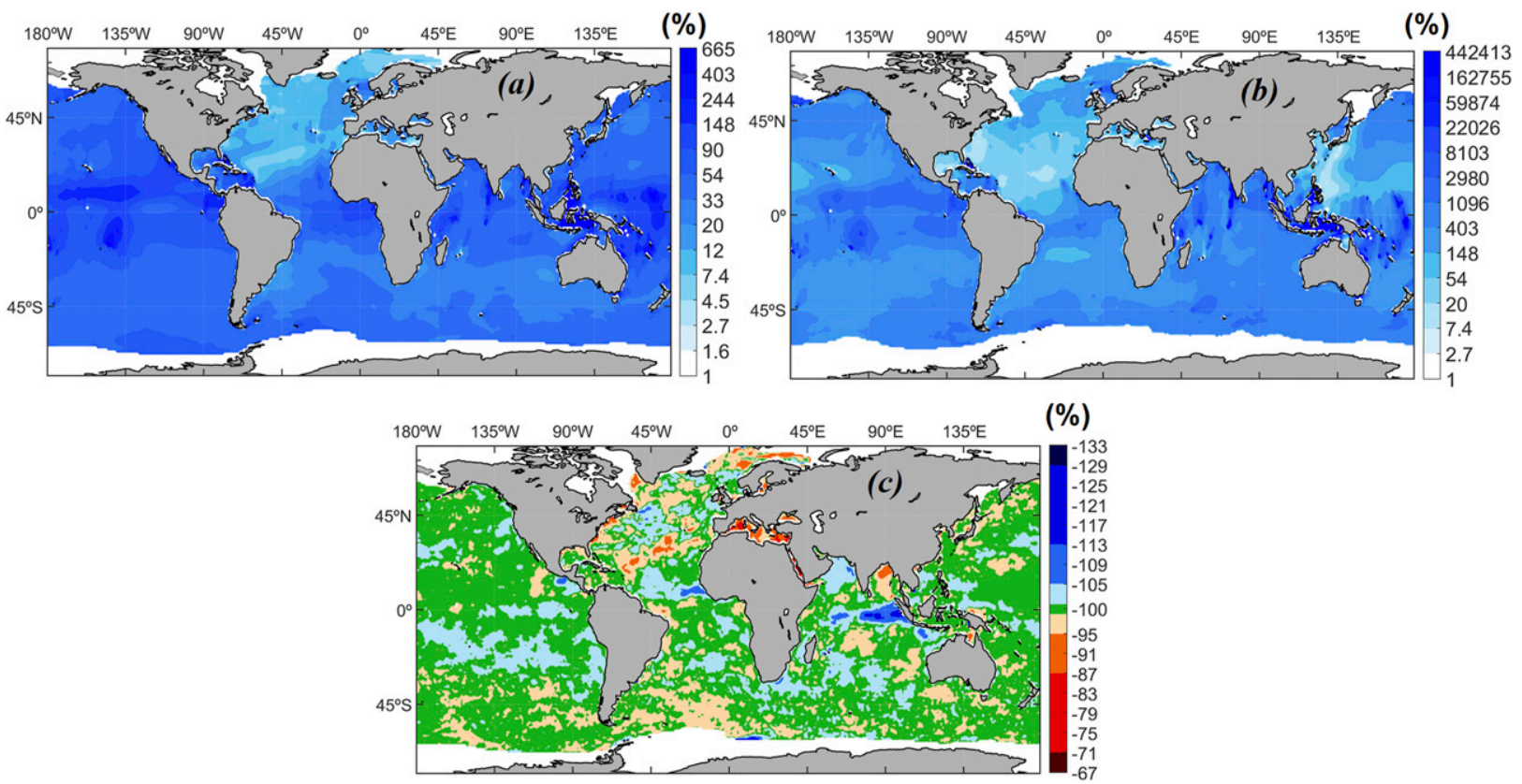

FIG. 7. As in Fig. 6, but for $T_{m}$. The color scales vary among the panels.

fluctuations, generally from $-67 \%$ to $-133 \%$, are still consistent with a decrease in the YK values, after bias correction. The better agreement between the original PC20 and ERA5 $H_{S}$ in these areas (Fig. 1a) is responsible for lower original YK values, which are more sensitive to small variations, after bias correction, leading to a higher range of YK normalized differences.

Figure 7 is similar to Fig. 6, but for $T_{m}$ (DAVs and YK). In both Figs. $7 \mathrm{a}$ and $7 \mathrm{~b}$, the higher DAVs are present along the tropical and subtropical latitudes of both hemispheres, the areas where the increases in the PDF scores, after bias correction, were higher. Similar to what was shown in in Figs. $6 \mathrm{a}$ and $6 \mathrm{~b}$, the DAVs in Figs. $7 \mathrm{a}$ and $7 \mathrm{~b}$ show increases in the original PDF scores of up to one and three orders of magnitude, considering the entire $T_{m}$ distribution and the $T_{m}$ values above the 99th quantile, respectively. The $T_{m} \mathrm{YK}$, relative to ERA5, also show lower values, after bias correction, across the global ocean, in Fig. $7 \mathrm{c}$. Changes from $-95 \%$ to $-105 \%$ are present everywhere except for the North Atlantic subbasin and the Mediterranean Sea, in which the normalized differences range is higher (from $-71 \%$ to $-113 \%$ ), as a result of the better agreement between the original PC20 and ERA5 $T_{m}$ in these areas (Fig. 2a).

\section{b. Bias-corrected wave climate projections toward the end of the twenty-first century}

To correct the biases for the $H_{S}, T_{m}$ and MWD projections, the same corrections terms obtained for the
PC20 time slice (1979-2005) were applied to the FC21 time slice (2081-2100). For that matter, the bias properties are considered stationary throughout the present and future period simulations. The bias-corrected future projections are presented by comparing the bias-corrected FC21 with the bias-corrected PC20-C (1986-2005) time slice, following the COWCLIP standards (Hemer et al. 2012). The projected wave climate changes are assessed through normalized differences for $H_{S}, T_{m}$, and $P_{w}$ (FC21 minus PC20-C normalized by PC20-C), and absolute differences for MWD (FC21 minus PC20-C). The results are analyzed for annual and seasonal [DecemberFebruary (DJF) and June-August (JJA)] means. The statistical significance of the projected changes was computed using standard $t$ test for difference in means. The shading in panels a and $b, d$ and $e$, and $g$ and $h$ of Figs. 8-11 and 13, described in more detail below, correspond to statistically nonsignificant areas at the $99 \%$ confidence level. Because of the reduced intermember uncertainty of the ensemble, most of the projected changes are statistically significant.

\section{1) SignificANT WAVE HeIGHT}

Figure 8 shows the annual and seasonal original and bias-corrected mean $H_{S}$ projected changes, as well as the differences between the original and bias-corrected projections. The hatching in Figs. 8c, 8f, and 8i outlines areas where the magnitude of the original projected changes (positive or negative) decreased after the bias correction (the same applies for Figs. 9-11 and 13, 

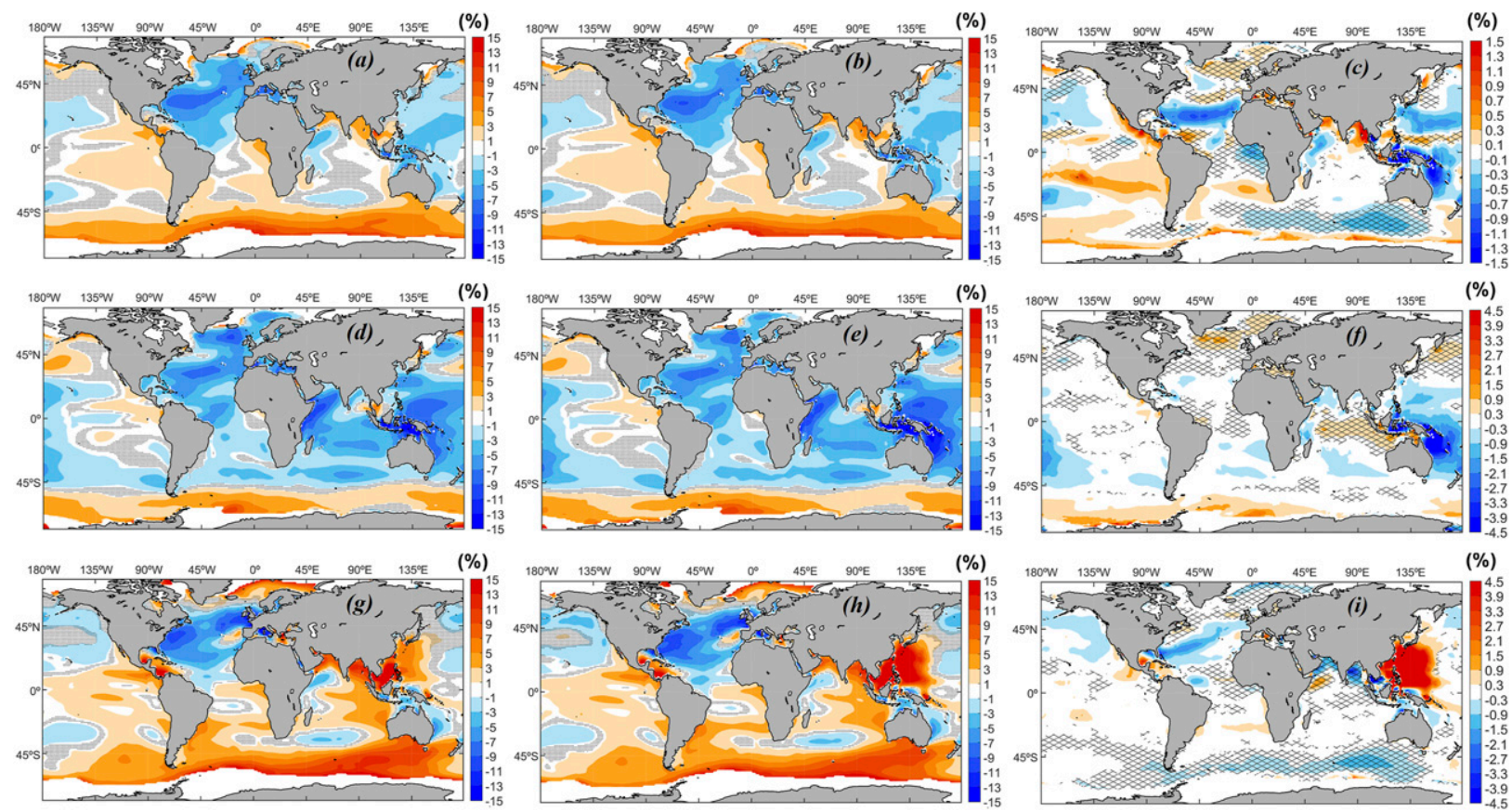

FIG. 8. (a)-(c) Annual, (d)-(f) DJF, and (g)-(i) JJA (left) original and (center) bias-corrected mean $H_{S}$ projected changes (normalized differences: FC21 minus PC20-C normalized by PC20-C; \%), along with (right) the absolute differences (\%) between the bias-corrected and original ensemble mean projected changes (between their normalized differences). The gray shading in (a), (b), (d), (e), (g), and (h) corresponds to areas without statistically significant (at $99 \%$ confidence level) projected changes. The hatching in (c), (f), and (i) outlines areas where the absolute magnitude of the original projected changes decreased after the bias correction. The color scales are different among panels. The original and bias-corrected PC20-C mean $H_{S}$ are shown in supplemental Fig. SM5.

described below). The annual and seasonal (DJF and JJA) original and bias-corrected PC20-C mean $H_{S}$ are presented in Fig. SM5 of the online supplemental material.

Upon the correction of the biases, the PC20-C annual and seasonal mean $H_{S}$ patterns have been maintained (Fig. SM5), however, the bias-corrected mean wave heights tend to be lower, especially in the Southern Hemisphere. This reduction is due to the original PC20 annual mean $H_{S}$ overestimation (Figs. 1 a and 4; supplemental Fig. SM2 and Table SM1) that is now corrected. The bias-corrected annual mean $H_{S}$ projections (Fig. 8b) show increases in wave heights in most of the Southern Hemisphere, reaching 14\% in the Atlantic and Indian sectors of the Southern Ocean. These projected increases in the annual mean $H_{S}$ tend to propagate northward, along the eastern halves of the Atlantic, Pacific, and Indian Oceans (across the swell pools; Chen et al. 2002; Semedo et al. 2011, 2018), due to swell propagation. The projected decreases on the annual mean $H_{S}$ are more confined to the Northern Hemisphere, especially in the North Atlantic subbasin, where expected decreases of $-10 \%$ are noticeable. The western Pacific is also dominated by projected decreases on annual mean $H_{S}$; however, they are lower, not exceeding $-7 \%$.
The comparison between the bias-corrected and original annual mean $H_{S}$ projected changes shows increases in the magnitudes of the original projected changes in most areas of the global ocean (unhatched areas in Fig. 8c), after the correction of the biases. The reader is warned that, in this case, we are referring to differences between the normalized differences (projected changes), with increased (decreased) magnitude when the bias-corrected projected changes are higher (lower) than the original, in absolute value. The increases in the magnitude of the original projected changes on the annual mean $H_{S}$ reach $0.9 \%$ in the higher latitudes and $1.3 \%$ in the subtropical latitudes of the eastern Pacific. Enhanced projected increases, after bias correction, are also noticeable in some areas of the north Indian subbasin (2\%). Enhanced projected decreases, on the other hand, are visible mainly in the subtropical latitudes of the North Atlantic and North Pacific subbasins, reaching $-1.1 \%$ and $-0.7 \%$, respectively.

The bias-corrected projected changes for the DJF mean $H_{S}$ (Fig. 8e) show decreases in most areas of the global ocean, down to $-11 \%$ and $-15 \%$ in the Arabian and in the Arafura Seas, respectively. Exceptions are the Southern Ocean and areas of the North Pacific subbasin, where increases of up to $11 \%$ and $5 \%$, respectively, can 
be expected during DJF. For the JJA mean $H_{S}$ (Fig. 8h), on the other hand, the bias-corrected projections show mostly increases. In the Southern Hemisphere, positive $H_{S}$ changes, locally up to $15 \%$ (Southern Ocean) can be expected. Projected increases of up to $15 \%$ are also visible in the South China Sea, Bay of Bengal, Caribbean Sea, Gulf of Mexico, and in the Arctic Ocean (probably due to an extended reduction of the SIC during JJA). In the North Atlantic and Pacific subbasins, the bias-corrected projected changes are negative during JJA, down to $-13 \%$ and $-5 \%$, respectively. The comparison between the bias-corrected and the original DJF and JJA mean $H_{S}$ projected changes (unhatched areas in Figs. 8f and 8i) shows increases in magnitude mostly in the Southern (Northern) Hemisphere during DJF (JJA). An enhancement of the original projected decreases in the Coral Sea during DJF, in $-5 \%$, is visible, as well as an enhancement of the original projected increases in the Philippines Sea during JJA, in $8 \%$. For the annual, DJF and JJA mean $H_{S}$, the global ocean area where projected increases are expected to occur increased after bias correction, from $58.8 \%$ to $59.0 \%, 31.6 \%$ to $31.9 \%$, and $68.7 \%$ to $69.6 \%$, respectively (Table 2 ).

Figure 9 and Fig. SM6 (in the online supplemental material) are similar to Fig. 8 and supplemental Fig. SM5, but for the extreme $H_{S}$. After bias correction a slight reduction of the extreme mean $H_{S}$ is noticeable, especially in the Southern Hemisphere, where the original PC20 overestimated the $H_{S}$ upper quantiles (Fig. SM2). The bias-corrected projected changes for the extreme mean $H_{S}$ (Fig. 9b) show increases of up to $15 \%$ in the Southern Ocean, and between $1 \%$ and $5 \%$ along the swell pools. Increases can also be expected in the northern areas of the Indian Ocean (e.g., Bay of Bengal and Arabian Sea; up to $15 \%$ ), and in the higher latitudes of the North Atlantic and North Pacific subbasins (up to 7\%). Nevertheless, an attenuation of the original projected changes on the extreme mean $H_{S}$ is visible after bias correction (hatched in Fig. 9c), mainly in the extratropical latitudes of both hemispheres (between 1\% and 3\%).

During DJF, the bias-corrected projected changes (Fig. 9e) in the western tropical Pacific and western tropical south Indian Ocean (east of Madagascar) show decreases down to $-22 \%$. These correspond to an enhancement of the original projected decreases of $-9 \%$ and $-7.8 \%$, respectively. During JJA, the bias-corrected projected changes (Fig. 9h) in the tropical and subtropical areas of the western North Atlantic reach $-26 \%$, corresponding to an enhancement of the original projected decreases in $-9 \%$. Bias-corrected projected increases of up to $40 \%$ are visible in the Philippines Sea, during JJA, corresponding to an enhancement of the original projected increases in $15 \%$. All the areas mentioned before
TABLE 2. Percentage of the global ocean area where projected increases and decreases in the ensemble's $H_{S}$ are expected to occur, considering the original and bias corrected projections.

\begin{tabular}{ccccc}
\hline \hline & $\begin{array}{c}H_{S} \text { OR } \\
\text { increase }\end{array}$ & $\begin{array}{c}H_{S} \mathrm{BC} \\
\text { increase }\end{array}$ & $\begin{array}{c}H_{S} \text { OR } \\
\text { decrease }\end{array}$ & $\begin{array}{c}H_{S} \mathrm{BC} \\
\text { decrease }\end{array}$ \\
\hline \multicolumn{5}{c}{ Mean } \\
Annual & 58.8 & 59.0 & 41.2 & 41.0 \\
DJF & 31.6 & 31.9 & 68.4 & 68.1 \\
JJA & 68.7 & 69.6 & 31.3 & 30.4 \\
& \multicolumn{5}{c}{ Extreme } \\
Annual & 55.2 & 57.9 & 44.8 & 42.1 \\
DJF & 34.8 & 40.7 & 65.2 & 59.3 \\
JJA & 63.0 & 68.3 & 37.0 & 31.7 \\
\hline
\end{tabular}

are in the path of tropical cyclones. The enhancement of the original projected changes there is possibly due to the misrepresentation of local tropical phenomena in the original PC20, when compared with ERA5.

For the annual, DJF, and JJA extreme mean $H_{S}$, the global ocean area where projected increases are expected to occur increased after bias correction, from $55.2 \%$ to $57.9 \%, 34.8 \%$ to $40.7 \%$, and $63.0 \%$ to $68.3 \%$, respectively (Table 2 ).

\section{2) MEAN WAVE PERIOD}

Figure 10 and Fig. SM7 (in the online supplemental material) are similar to Fig. 8 and supplemental Fig. SM5, but for the annual mean $T_{m}$. After the correction of the (mostly) positive biases (Figs. 2a and 5; supplemental Fig. SM2 and Table SM1), the PC20-C annual and seasonal mean $T_{m}$ patterns have been maintained, showing nevertheless a consistent reduction of the original mean wave periods (within 1-2 s; Fig. SM7).

The bias-corrected projected changes in the annual mean $T_{m}$ (Fig. 10b) show increases mainly in the Southern Hemisphere and along the swell pools, up to $4.5 \%$, consistent with the projected increases on the annual mean $H_{S}$ in the same areas (Fig. 8b). Projected decreases can be expected in the North Atlantic subbasin (including the Mediterranean and Baltic Seas) and in the western half of the Pacific basin, down to $-5.5 \%$. The comparison between the bias-corrected and the original projected changes shows increased magnitudes in most of the global ocean, after bias correction (Fig. 10c). Enhanced projected increases are noticeable in the eastern halves of the Atlantic and Pacific basins, peaking in the tropical areas (swell pools), at $1.5 \%$ of the original projected increases. In the North Atlantic subbasin and in the western half of the Pacific basin, enhanced projected decreases in the annual mean $T_{m}$ are noticeable: $-0.9 \%$ and $-1.5 \%$, respectively. 

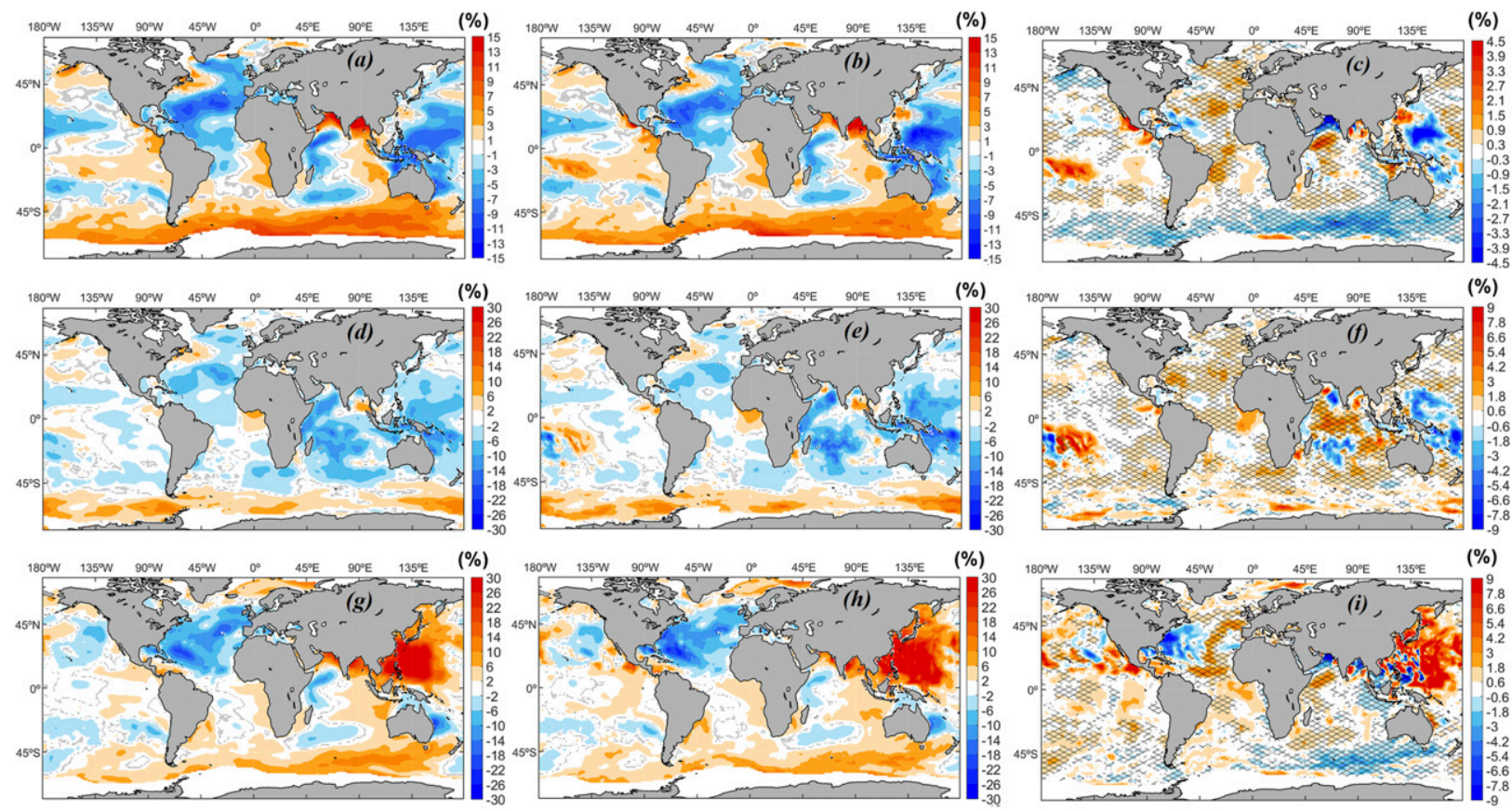

FIG. 9. As in Fig. 8, but for the extreme mean. bias-corrected extreme mean $H_{S}$ (mean for values higher than the 99th quantile) The original and bias-corrected PC20-C extreme mean $H_{S}$ are shown in supplemental Fig. SM6.

During DJF, decreases in the bias-corrected mean $T_{m}$ can be expected in most of the Northern Hemisphere, down to $-4.5 \%$ (Fig. 10e). Exceptions are the eastern half of the North Pacific subbasin (up to $4.5 \%$ ), the north
Indian subbasin (up to $6.5 \%$ ) and the Arctic (up to $5.5 \%$, possibly due to a reduction of the SIC). Projected increases of up to $4.5 \%$ are visible in the Southern Hemisphere, mainly in the swell pools. During JJA,
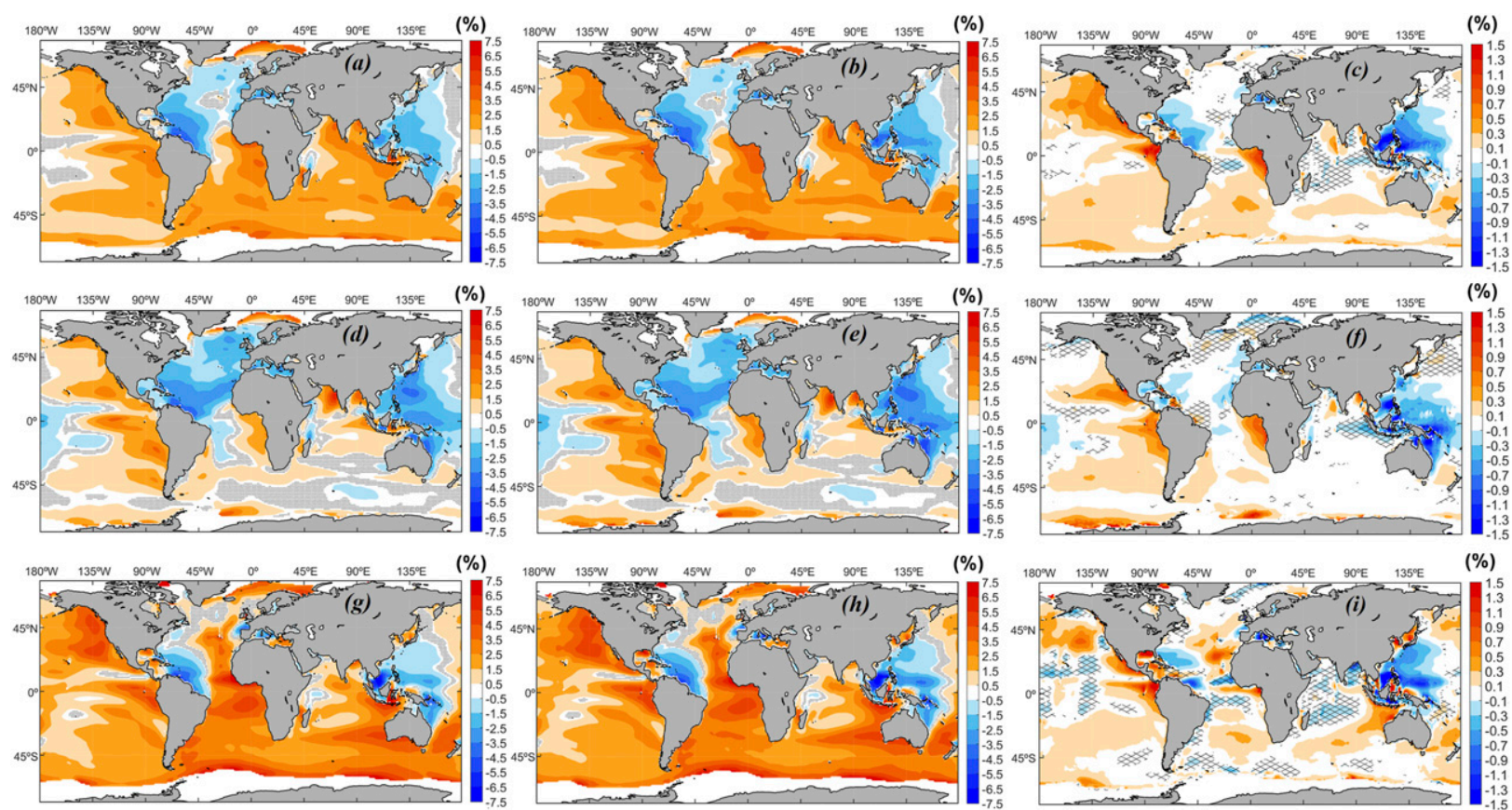

FIG. 10. As in Fig. 8, but for $T_{m}$. The original and bias-corrected PC20-C mean $T_{m}$ are shown in supplemental Fig. SM7. 
projected increases of up to $7.5 \%$ are visible across most of the global ocean (Fig. 10h). Exceptions are the North Atlantic subbasin and the western half of the Pacific basin. For both seasons, after bias correction, increased projected magnitudes are visible especially in the tropical areas of both hemispheres (less than $2 \%$; Figs. 10f,i).

For the annual, DJF and JJA mean $T_{m}$, the global ocean area where projected increases are expected to occur increased after bias correction from $77.7 \%$ to $78.2 \%, 59.9 \%$ to $60.3 \%$, and $86.3 \%$ to $86.8 \%$, respectively (Table 3 ).

Figure 11 and Fig. SM8 (in the online supplemental material) are similar to Fig. 9 and supplemental Fig. SM6, but for the extreme mean $T_{m}$. The biascorrected projected changes in the extreme mean $T_{m}$ (Fig. 11b) show increases of up to $5.5 \%$ (decreases down to $-5.5 \%$ ) in the Southern (Northern) Hemisphere. These changes tend to be higher in the tropical latitudes. The projected increase in the extreme mean $T_{m}$ along swell pools is also consistent with the projected increase on the extreme mean $H_{S}$ in the Southern Ocean (Fig. 9b). After the biases have been corrected, the projected changes in the extreme mean $T_{m}$ show increased magnitudes in the tropical latitudes of both hemispheres (unhatched areas in Fig. 11c), mainly between $0.3 \%$ and $0.9 \%$.

The bias-corrected DJF projected changes in the extreme mean $T_{m}$ (Fig. 11e) show increases in the Indian Ocean, and in the South Atlantic and Pacific subbasins, mainly between $1 \%$ and $3 \%$, but up to $9 \%$. Projected decreases can be seen in the North Atlantic and western half of the Pacific basin, down to $-3 \%$ and $-7 \%$, respectively. During JJA (Fig. 11h), the bias-corrected projected increases reach $15 \%$ in the Gulf of Mexico, and in the Caribbean, Arafura, Java, Celebes, and Sulu Seas. Projected increases are also visible covering part of the North Atlantic subbasin, up to $11 \%$. Projected decreases during JJA peak at and $-11 \%$ in the Caribbean Sea. After bias correction, increased magnitudes are visible, during DJF (Fig. 11f), in most of the Southern Hemisphere and in the Arabian Sea $(3.3 \%$ and $4.5 \%$, respectively), and during JJA (Fig. 11i), mostly in the Northern Hemisphere and in the Indonesian archipelago. In the tropical latitudes of the North Atlantic subbasin (e.g., Caribbean Sea and Gulf of Mexico), the differences between the bias-corrected and original JJA projected changes in the extreme mean $T_{m}$ range from $-4.5 \%$ to $10 \%$. Such large differences possibly arose due to the misrepresentation of local tropical phenomena in the original $\mathrm{PC} 20$, which resulted in higher volatility among the bias-correction parameters, then transferred to the bias-corrected FC21.
TABLE 3. As in Table 2, but for $T_{m}$.

\begin{tabular}{ccccc}
\hline \hline & $\begin{array}{c}T_{m} \text { OR } \\
\text { increase }\end{array}$ & $\begin{array}{c}T_{m} \text { BC } \\
\text { increase }\end{array}$ & $\begin{array}{c}T_{m} \text { OR } \\
\text { decrease }\end{array}$ & $\begin{array}{c}T_{m} \text { BC } \\
\text { decrease }\end{array}$ \\
\hline \multicolumn{5}{c}{ Mean } \\
Annual & 77.7 & 78.2 & 22.3 & 21.8 \\
DJF & 59.9 & 60.3 & 40.1 & 39.7 \\
JJA & 86.3 & 86.8 & 13.7 & 13.2 \\
& \multicolumn{5}{c}{ Extreme } \\
Annual & 78.1 & 79.6 & 21.9 & 20.4 \\
DJF & 66.4 & 72.1 & 33.6 & 27.9 \\
JJA & 75.4 & 79.4 & 24.6 & 20.6 \\
\hline
\end{tabular}

For the annual, DJF and JJA extreme mean $T_{m}$, the global ocean area where projected increases are expected to occur increased after bias correction, from $78.1 \%$ to $79.6 \%, 66.4 \%$ to $72.1 \%$, and $75.4 \%$ to $79.4 \%$, respectively (Table 3).

\section{3) MeAn waVe DiReCTION}

Figure 12 and Fig. SM9 (in the online supplemental material) are similar to Fig. 8 and supplemental Fig. SM5, but for the mean MWD. The attenuation of swell propagation from the Southern Ocean, after the correction of the biases, is visible in Fig. SM9. Greater differences are noticeable during JJA (Figs. SM9e,f), with a less southerly component at the swell pools.

The bias-corrected projected changes in the annual mean MWD (Fig. 12b) show counterclockwise rotations, mainly along the extratropical latitudes of both hemispheres (mostly between $-3^{\circ}$ and $-15^{\circ}$ ), and clockwise rotations along the tropical and subtropical ones. This pattern is in agreement with an enhancement of the swell propagation from the Southern Ocean (as seen in Figs. 8-11), but also with a pronounced decrease in the SIC in the higher latitudes of the Northern Hemisphere. The comparison between the bias-corrected and original projected changes in the annual mean MWD (Fig. 12c) shows higher differences in the Northern Hemisphere.

For both seasons (DJF and JJA), the bias-corrected projected changes on the mean MWD (Figs. 12e,h) show counterclockwise (clockwise) rotations mainly along the extratropical (tropical and subtropical) latitudes, similarly to the bias-corrected projected changes on the annual mean MWD, in Fig. 12b. The highest projected changes on the seasonal mean MWD take place in the tropical and subtropical latitudes of the respective summer hemisphere, probably due to local phenomena. This is also where greater differences in the seasonal mean MWD projected changes occur, after the correction of the biases (e.g., southeastern of the Pacific basin during DJF and Philippines Sea during JJA; Figs. 12f,i). 

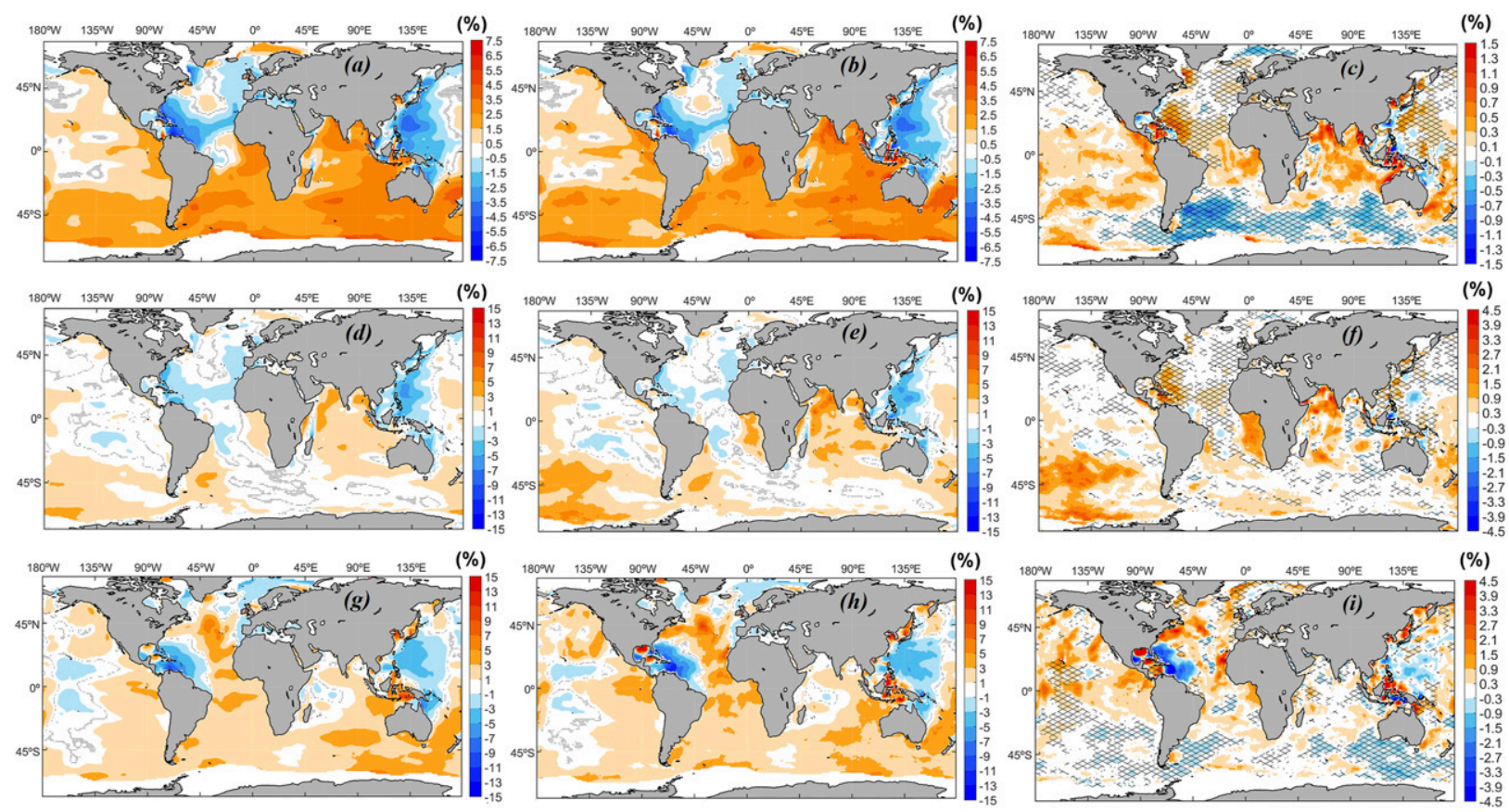

FIG. 11. As in Fig. 9, but for $T_{m}$. The original and bias-corrected PC20-C extreme mean $T_{m}$ are shown in supplemental Fig. SM8.

\section{4) WAVE ENERGY FLUX}

The wave energy flux $\left(P_{w} ; \mathrm{kW} \mathrm{m}^{-1}\right)$ projected changes were also computed, for both the original and the bias-corrected instances. Given the greater impacts of the extreme events, only the extreme mean $P_{w}$ is considered. Figure 13 and Fig. SM10 (in the online supplemental material) are similar to Fig. 9 and supplemental Fig. SM6, but for the extreme mean $P_{w}$. The extreme $P_{w}$ means are generally reduced after bias correction (Fig. SM10). This reduction (Figs. SM10a,b) exceeds $300 \mathrm{~kW} \mathrm{~m}^{-1}$ in the Northern Hemisphere (from above 1100 to below $800 \mathrm{~kW} \mathrm{~m}^{-1}$ ), and $400 \mathrm{~kW} \mathrm{~m}^{-1}$ in the Southern Hemisphere (from 1000 to $600 \mathrm{~kW} \mathrm{~m}^{-1}$ ). Such differences between the bias-corrected and original PC20C extreme mean $P_{w}$ values can be attributed to the original PC20 extreme mean $H_{S}$ and $T_{m}$ overestimation, visible in Figs. $1 \mathrm{~b}$ and 2b, but also in Figs. 4 and 5, and in supplemental Figs. SM2 and SM3 and Table SM1.

The bias-corrected projected changes in the extreme mean $P_{w}$ (Fig. 13b) show consistent increases between $10 \%$ and $30 \%$ in the Southern Ocean, and up to $18 \%$ along the swell pools. Projected increases of up to $30 \%$ and $18 \%$ are also visible along the northern areas of the Indian basin (e.g., Bengal Bay and Arabian Sea) and in the higher latitudes of the North Atlantic and Pacific subbasins, respectively. The comparison between the bias-corrected and the original projected changes in the extreme mean $P_{w}$ shows decreased magnitudes, after bias correction, mainly in the Southern Ocean and in the North Atlantic subbasin (hatched areas in Fig. 13c), with an attenuation between $1.8 \%$ and $5.4 \%$. Increased magnitudes are visible in the swell pools, Philippines Sea, Gulf of Mexico, Caribbean Sea, and higher latitudes. These increases in the magnitude of the original projected changes in the extreme mean $P_{w}$ ascend to $9 \%$.

During DJF (Fig. 13e), the bias-corrected projected changes show decreases in the extreme mean wave energy fluxes in the North Atlantic subbasin, down to $-20 \%$, and in the western tropical Pacific and western areas of the Indian Ocean, down to $-36 \%$ and $-42 \%$, respectively. These correspond to an enhancement of the original projected decreases in $-22.5 \%$ and $-16.5 \%$, respectively. The bias-corrected projected increases during DJF take place mainly in the Southern Ocean, between $12 \%$ and $44 \%$, corresponding to an enhancement of the original projected increases in more than $20 \%$ in the higher latitudes (Fig. 13f). During JJA (Fig. 13h), the bias-corrected projected changes show increases in the extreme mean $P_{w}$ mainly in the Southern Ocean, swell pools and in the North Pacific subbasin (especially the western half-Philippines Sea). These projected increases are up to $36 \%, 20 \%$, and $120 \%$, respectively. Considerable decreases can be expected in the North Atlantic, mostly between $-4 \%$ and $-28 \%$, reaching $-52 \%$ east of the Bermuda archipelago. During JJA (Fig. 13i), increased magnitudes are visible 

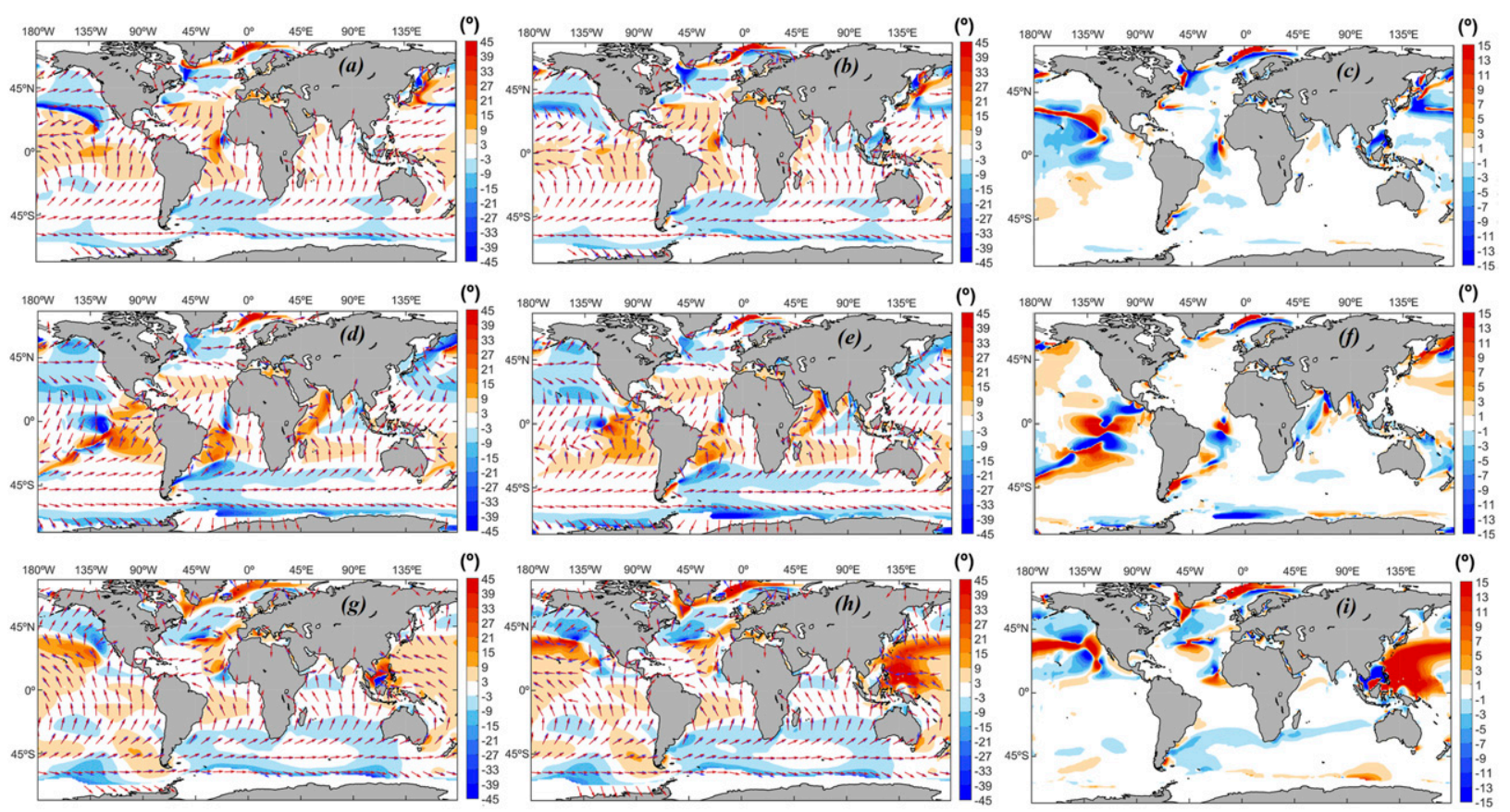

FIG. 12. (a)-(c) Annual, (d)-(f) DJF, and (g)-(i) JJA (left) original and (center) bias-corrected mean MWD projected changes (absolute differences: FC21 minus PC20-C; ${ }^{\circ}$ ) [blue arrows show the (original and bias corrected) PC20-C MWD, and red arrows show the (original and bias corrected) FC21 MWD], along with (right) the absolute differences $\left(^{\circ}\right)$ between the bias-corrected and original ensemble mean projected changes (between their absolute differences). The color scales are different among panels. The original and bias-corrected PC20-C mean MWD are shown in supplemental Fig. SM9.

mainly in the Northern Hemisphere, reaching $20 \%$ in several areas of the western North Pacific, and $-19.5 \%$ in the western North Atlantic. Most of the areas in which bias correction resulted in increased magnitudes are within the path of tropical cyclones, therefore such enhancements are possibly related to the misrepresentation of local tropical phenomena in the original PC20.

For the annual, DJF and JJA extreme mean $P_{w}$, the global ocean area where projected increases are expected to occur increased after bias correction, from $62.1 \%$ to $67.1 \%, 38.1 \%$ to $49.4 \%$, and $65.5 \%$ to $72.2 \%$, respectively (Table 4$)$.

\section{Summary and conclusions}

A seven-member dynamic single-forcing (EC-EARTH), single-model (WAM), and single-scenario (RCP8.5) ensemble of wave climate simulations was submitted to a bias-correction procedure, using a method that is based on the differences between the simulated and the reference quantiles (EGQM and EQM), first applied to global wave climate projections by Lemos et al. (2020). The most recent ECMWF reanalysis has been used as reference. The original biases were computed for the PC20 (1979-2005) time slice, for the $H_{S}, T_{m}$, and MWD wave parameters.
The original $H_{S}$ biases (annual mean, and extreme mean: mean above the 99th quantile) showed a consistent overestimation by the PC20 ensemble, relative to ERA5, especially in the extratropical latitudes of both hemispheres for extreme $H_{S}$ values (Figs. 1a,b and 4; supplemental Fig. SM2; Table 1). Note that the ERA5 tends to slightly underestimate both the mean and extreme $H_{S}$ (Bidlot et al. 2019), when compared with observations and previous reanalyzes/hindcasts, which could have resulted in increased original biases for the $H_{S}$. A generalized overestimation by the original PC20 ensemble was also shown for the $T_{m}$, with highest biases along the swell pools (Figs. 2a,b and 5; supplemental Fig. SM3; Table 1). For the MWD, the highest biases were shown to be present along the tropical and subtropical latitudes of both hemispheres (Fig. 3a; supplemental Fig. SM4; Table 1). After the bias correction (using the EGQM method for $H_{S}$ and $T_{m}$, and the EQM method for MWD), biases were shown to have reduced between two and three orders of magnitude, to values generally below $0.01 \mathrm{~m}$ for $H_{S}$ (Figs. $1 \mathrm{c}, \mathrm{d}$ and Table 1 ), $0.01 \mathrm{~s}$ for $T_{m}$ (Figs. 2c,d and Table 1), and $0.2^{\circ}$ for MWD (Fig. $3 b$ and Table 1).

The PDF scores for the $H_{S}$ and $T_{m}$ parameters were also shown to have improved considerably after bias correction, in Figs. 6a,b and 7a,b, respectively. These 

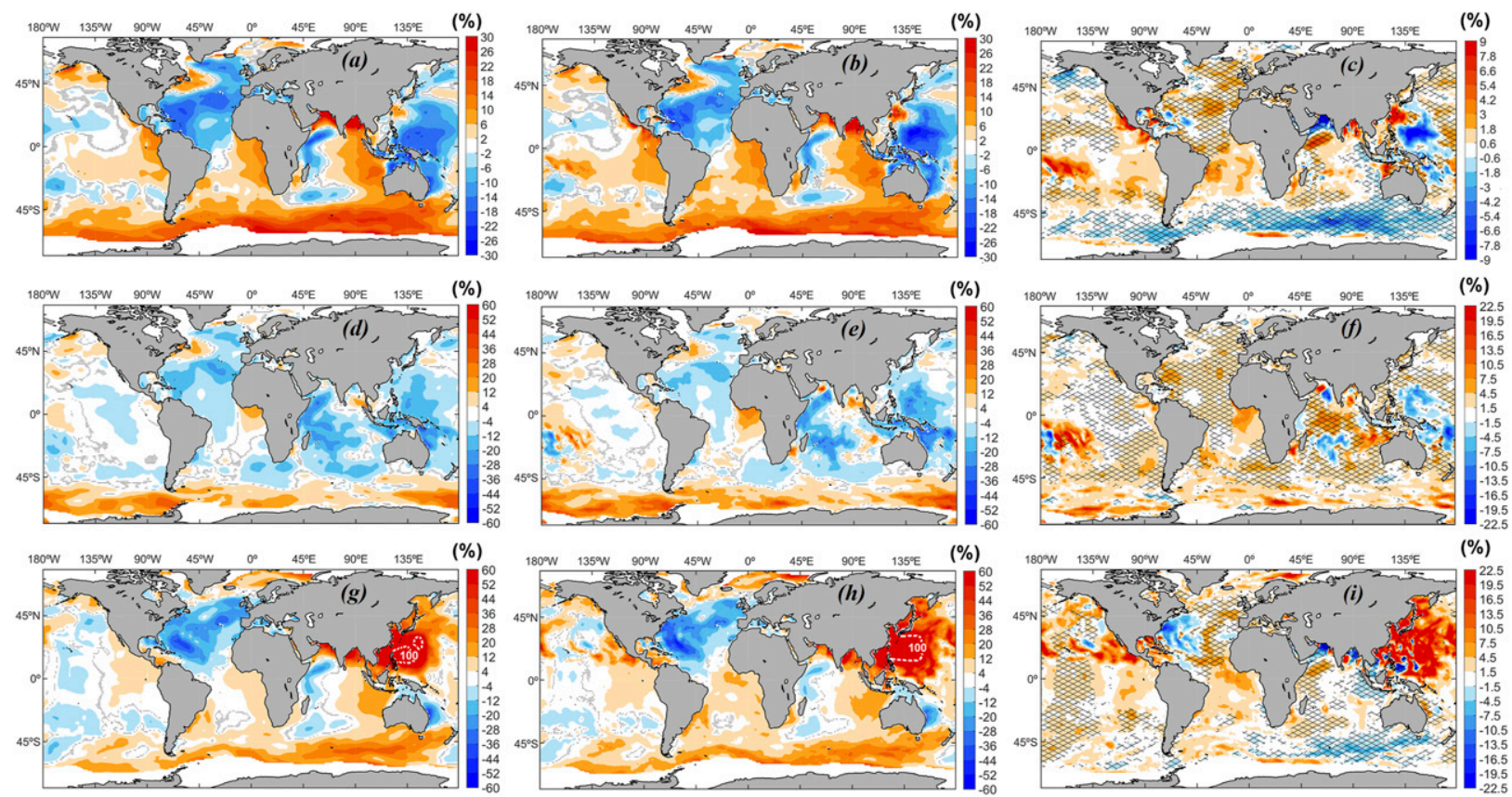

FIG. 13. As in Fig. 9, but for $P_{w}$. The original and bias-corrected PC20-C extreme mean $P_{w}$ are shown in Fig. supplemental SM10.

improvements were particularly striking along the tropical and subtropical latitudes of both hemispheres, where the original PDF scores were lower (higher mismatch between the PC20 and the ERA5 distributions). The skewness of the PC20 and ERA5 $H_{S}$ and $T_{m}$ distributions were also shown to be in a greater agreement after the biases were corrected, as seen by the normalized differences between the bias-corrected and original YuleKendall skewness measures, between $-99 \%$ and $-101 \%$ in large areas of the global ocean, which can be translated in skewness deviations below $1 \%$ upon the correction of the biases, in these areas.

The same bias-correction parameters applied to the $H_{S}, T_{m}$, and MWD during PC20 time slice, were applied to the future projections FC21 (2081-2100) time slice, considering that the original biases properties are propagated throughout the simulations (i.e., the longterm deviations with reference to ERA5 are kept constant until the end of the twenty-first century), a fundamental assumption of climate bias-correction studies (Lemos et al. 2020; Wood et al. 2004; Wang et al. 2010; Amengual et al. 2012; Charles et al. 2012). The bias-corrected projections were shown and compared to the original ones in Figs. 8-13.

Considering the annual mean and extreme mean $H_{S}$, the bias-corrected projections showed increases mainly in the Southern Hemisphere and decreases mainly in the Northern Hemisphere. In the Southern Ocean and North Atlantic subbasin, bias-corrected projected changes of $14 \%$ and $-10 \%$, respectively, for the annual mean $H_{S}$ and of $15 \%$ and $-11 \%$, respectively, for the extreme mean $H_{S}$ were shown to be visible in Figs. $8 \mathrm{~b}$ and $9 \mathrm{~b}$. The seasonal bias-corrected projected changes were shown to depict mostly decreases in the mean and extreme $H_{S}$ during DJF and increases in JJA. Increased magnitudes, after bias correction of the annual mean $H_{S}$ projections, were shown to be visible in most of the global ocean (Fig. 8c). However, for the bias-corrected extreme mean $H_{S}$ projections, increased magnitudes were only shown to be visible along the tropical and subtropical latitudes (Fig. 9c), especially in the summer hemisphere (Figs. 9f,i). This pattern is consistent with the misrepresentation of the tropical cyclones in PC20, which possibly led to increased extreme $H_{S}$ projections magnitudes in these areas. Altogether, the

TABLE 4. As in Table 2, but for $P_{w}$.

\begin{tabular}{ccccc}
\hline \hline & $\begin{array}{c}P_{w} \text { OR } \\
\text { increase }\end{array}$ & $\begin{array}{c}P_{w} \text { BC } \\
\text { increase }\end{array}$ & $\begin{array}{c}P_{w} \text { OR } \\
\text { decrease }\end{array}$ & $\begin{array}{c}P_{w} \text { BC } \\
\text { decrease }\end{array}$ \\
\hline \multicolumn{5}{c}{ Mean } \\
Annual & 66.5 & 67.4 & 33.5 & 32.6 \\
DJF & 36.7 & 38.0 & 63.3 & 62.0 \\
JJA & 76.2 & 77.6 & 23.8 & 22.4 \\
& \multicolumn{5}{c}{ Extreme } \\
Annual & 62.1 & 67.1 & 37.9 & 32.9 \\
DJF & 38.1 & 49.4 & 61.9 & 50.6 \\
JJA & 65.5 & 72.2 & 34.5 & 27.8 \\
\hline
\end{tabular}


bias-corrected projected changes for the $H_{S}$ are consistent with the results from previous studies, showing, however, higher projected increases in the tropical and subtropical latitudes (especially in the Southern Hemisphere), when compared, for example, with Semedo et al. (2013), Hemer et al. (2013a), and Morim et al. (2019).

The bias-corrected annual and extreme mean $T_{m}$ projections showed increases in most of the global ocean, up to $6.5 \%$ and $7.5 \%$, respectively. Such projected increases were shown to take place especially in the Southern Hemisphere and at the swell pools. Exceptions were shown to be the North Atlantic and western North Pacific, with projected decreases down to $-5.5 \%$. Seasonally, the bias-corrected projected increases were shown to be more striking during JJA, covering $86.8 \%$ of the global ocean. Increased magnitudes for the annual mean $T_{m}$ projected changes, after bias correction, were shown to be visible in most of the global ocean (Fig. 10c). For the extreme mean $T_{m}$, increased magnitudes were shown to be mostly confined to the tropical and subtropical latitudes (Fig. 11c), especially in the summer hemisphere (Figs. 11f,i). The bias-corrected projected changes for the $T_{m}$ are consistent with previous results in scientific literature (Semedo et al. 2013; Hemer et al. 2013a; Morim et al. 2019); however, slightly higher projected increases were found in the tropical and subtropical latitudes of the Southern Hemisphere, especially at the swell pools.

The bias-corrected projected changes in the annual mean MWD (Fig. 12b) showed counterclockwise rotations mainly along the extratropical latitudes of both hemispheres, and clockwise rotations along the tropical and subtropical latitudes. Such patterns are consistent with enhanced swell propagation from the Southern Ocean and reduced SIC in the Northern Hemisphere, in FC21. The bias-corrected projected changes for the MWD are in agreement with the results from Hemer et al. (2013a) and Morim et al. (2019).

The joint effects of the expected changes in the $H_{S}$ and $T_{m}$ climates were analyzed through the $P_{w}$ projections (only the extreme mean $P_{w}$ was considered). Biascorrected projected increases of up to $30 \%$ in the Southern Ocean and $18 \%$ in the swell pools and decreases down to $-18 \%$ in the North Atlantic subbasin were found. While these were shown to be slightly attenuated in magnitude (Fig. 13c), compared to the original projected changes, the seasonal extreme mean $P_{w}$ bias-corrected projections were shown to be increased in magnitude, mainly along the tropical and subtropical latitudes of the summer hemisphere (Figs. 13f,i), possibly due to the misrepresentation of seasonal extreme tropical phenomena, in PC20. For the western North Pacific (Philippines Sea), the bias-corrected projected changes on the JJA extreme $P_{w}$ were shown to ascend to $120 \%$.

The bias-corrected projected changes in wave climate described in this study are consistent with the results from previous studies. Nevertheless, enhanced projected increases on the annual and seasonal means were found for the $H_{S}$ and $T_{m}$, in the tropical and subtropical latitudes of both hemispheres. Such differences were shown to be more striking for the upper quantiles (extreme events; $P_{w}$ ). Note that, since a single-model, single-forcing ensemble, designed with the purpose of reducing the higher uncertainty inherent to multiforcing ensembles (and therefore with reduced intermember uncertainty), was used to produce the results, the projected changes shown in the present study are, in most cases, statistically significant at the $99 \%$ confidence level. However, the good performance of this ensemble in representing the current wave climate features, when evaluated through comparison with reanalysis/hindcast and in situ observations (Semedo et al. 2018) increases our confidence in the results, despite their reduced robustness.

The relevance of a quantile-based bias-correction method in the estimation of the projected changes in wave climate should be acknowledged, particularly because of its ability to deal with the misrepresentation local tropical phenomena, such as the effects of tropical cyclones. The application of this method (such as for other bias-correction methods) should, however, be limited to final output data-for example, to the wave parameters-instead of the to the winds prior to the forcing of the wave model(s). This principle should be kept to avoid extra sources of uncertainty (Hemer et al. 2012), and to prevent breaking the consistency of multivariate features between the simulated parameters.

The BC method used in this study has a purely mathematical nature, based on local differences between two distributions. Therefore, the results should be interpreted in the context of some limitations, such as the great sensitivity to the chosen reference dataset (ERA5), the assumption of a stationary bias (i.e., that the bias behavior in PC20 is propagated into the future climate projections maintaining its properties), and the use of an ensemble with reduced intermodel uncertainty. One way to increase the robustness of $\mathrm{BC}$ in climate analysis may be by including nonstationary and spatially dependent techniques.

Acknowledgments. This work has been done under the auspices of the JCOMM Coordinated Ocean Wave Climate Project (COWCLIP). Gil Lemos is supported by the EarthSystems Doctoral School, at University of Lisbon, supported by Portuguese Foundation for Science 
and Technology (FCT) project UIDB/50019/2020-Instituto Dom Luiz. Melisa Menendez acknowledges the financial support from the Ramon y Cajal Program (RYC-20146469) and project ECLISEA, part of ERA4CS/ERA-NET initiated by JPI Climate and cofounded by the European Union (Grant 690462).

\section{REFERENCES}

Aarnes, O. J., S. Abdalla, J.-R. Bidlot, Ø. Breivik, 2015: Marine wind and wave height trends at different ERA-Interim forecast ranges. J. Climate, 28, 819-837, https://doi.org/10.1175/ JCLI-D-14-00470.1.

——, M. Reistad, Ø. Breivik, E. Bitner-Gregersen, A. K. Magnusson, B. Natvig, and E. Vanem, 2017: Projected changes in significant wave height toward the end of the 21st century: Northeast Atlantic. J. Geophys. Res. Oceans, 122, 3394-3403, https://doi.org/10.1002/2016JC012521.

Alves, J. H. G. M., 2006: Numerical modelling of ocean swell contributions to the global wind-wave climate. Ocean Modell., 11, 98-122, https://doi.org/10.1016/j.ocemod.2004.11.007.

Amante, C., and B. W. Eakins, 2009: ETOPO1 1 Arc-minute Global Relief Model: Procedures, data sources and analysis. NOAA Tech. Memo. NESDIS NGDC-24, 25 pp., https://www.ngdc.noaa.gov/ $\mathrm{mgg} / \mathrm{global} / \mathrm{relief} / \mathrm{ETOPO} 1 /$ docs/ETOPO1.pdf.

Amengual, A., V. Homar, R. Romero, S. Alonso, and C. Ramis, 2012: A statistical adjustment of regional climate model outputs to local scales: Application to Platja de Palma, Spain. J. Climate, 25, 939-957, https://doi.org/10.1175/JCLI-D-1005024.1.

Applequist, S., 2012: Wind rose bias correction. J. Appl. Meteor. Climatol., 51, 1305-1309, https://doi.org/10.1175/JAMC-D-110193.1.

Babanin, A. V., M. Onorato, and F. Qiao, 2012: Surface waves and wave-coupled effects in lower atmosphere and upper ocean. J. Geophys. Res., 117, C00J01, https://doi.org/10.1029/ 2012JC007932.

Bheeroo, R. A., N. Chandrasekar, S. Kaliraj, and N. S. Magesh, 2016: Shoreline change rate and erosion risk assessment along the Trou Aux Biches-Mont Choisy beach on the northwest coast of Mauritius using GIS-DSAS technique. Environ. Earth Sci., 75, 444, https://doi.org/10.1007/s12665016-5311-4.

Bidlot, J.-R., G. Lemos, A. Semedo, C3S Reanalysis Team, and ECMWF, 2019: ERA5 reanalysis and ERA5-based ocean wave hindcast. Second Int. Workshop on Waves, Storm Surges and Coastal Hazards, Melbourne, VIC, Australia, University of Melbourne, R1, http://waveworkshop.org/ 16thWaves/Presentations/R1\%20Wave_Workshop_2019_ Bidlot_et_al.pdf.

Bitner-Gregersen, E. M., and O. Gramstad, 2018: Potential changes in the joint probabilistic description of the North Atlantic wave climate. Proc. ASME 2018 37th Int. Conf. on Ocean, Offshore and Arctic Engineering-OMAE2018, Madrid, Spain, ASME, OMAE2018-77592, https://doi.org/10.1115/OMAE2018-77592.

—, T. Hørte, L. I. Eide, and E. Vanem, 2015: Impact of climate change and extreme waves on tanker design. SNAME Maritime Convention 2014, Houston, TX, Society of Naval Architects and Marine Engineers, 288-304.

Boberg, F., P. Berg, P. Thejll, W. J. Gutowski, and J. H. Christensen, 2009: Improved confidence in climate change projections of precipitation evaluated using daily statistics from the PRUDENCE ensemble. Climate Dyn., 32, 10971106, https://doi.org/10.1007/s00382-008-0446-y.

Boé, J., L. Terray, F. Habets, and C. Martin, 2007: Statistical and dynamical downscaling of the Seine basin climate for hydro-meteorological studies. Int. J. Climatol., 27, 1643-1655, https://doi.org/10.1002/joc.1602.

Brands, S., S. Herrera, D. San-Martín, and J. M. Gutiérrez, 2011: Validation of the ENSEMBLES global climate models over southwestern Europe using probability density functions, from a downscaling perspective. Climate Res., 48, 145-161, https://doi.org/10.3354/cr00995.

Camus, P., I. J. Losada, C. Izaguirre, A. Espejo, M. Menéndez, and J. Pérez, 2017: Statistical wave climate projections for coastal impact assessments. Earth's Future, 5, 918-933, https://doi.org/ 10.1002/2017EF000609.

Casas-Prat, M., X. L. Wang, and N. Swart, 2018: CMIP5-based global wave climate projections including the entire Arctic Ocean. Ocean Modell., 123, 66-85, https://doi.org/10.1016/ j.ocemod.2017.12.003.

Cavaleri, L., L. Bertotti, and P. Lionello, 1991: Wind wave cast in the Mediterranean Sea. J. Geophys. Res., 96, 10 739-10764, https://doi.org/10.1029/91JC00322.

Charles, E., D. Idier, P. Delecluse, M. Déqué, and G. Le Cozannet, 2012: Climate change impact on waves in the Bay of Biscay, France. Ocean Dyn., 62, 831-848, https://doi.org/10.1007/ s10236-012-0534-8.

Chen, G., B. Chapron, R. Ezraty, and D. Vandemark, 2002: A global view of swell and wind sea climate in the ocean by satellite altimeter and scatterometer. J. Atmos. Oceanic Technol., 19, 1849-1859, https://doi.org/10.1175/1520-0426(2002) 019<1849:AGVOSA > 2.0.CO;2.

Copernicus Climate Change Service, 2017: ERA5: Fifth generation of ECMWF atmospheric reanalyses of the global climate. Copernicus Climate Change Service Climate Data Store (CDS), accessed 10 September 2019, https:// cds.climate.copernicus.eu/cdsapp\#!/home.

Dee, D. P., and Coauthors, 2011: The ERA-Interim reanalysis: Configuration and performance of the data assimilation system. Quart. J. Roy. Meteor. Soc., 137, 553-597, https://doi.org/ 10.1002/qj.828.

Déqué, M., 2007: Frequency of precipitation and temperature extremes over France in an anthropogenic scenario: Model results and statistical correction according to observed values. Global Planet. Change, 57, 16-26, https://doi.org/10.1016/j.gloplacha.2006.11.030.

Fan, Y., I. M. Held, S.-J. Lin, and X. L. Wang, 2013: Ocean warming effect on surface gravity wave climate change for the end of the twenty-first century. J. Climate, 26, 6046-6066, https://doi.org/10.1175/JCLI-D-12-00410.1.

Ferro, C., A. Hannachi, and D. Stephenson, 2005: Simple nonparametric techniques for exploring changing probability distributions of weather. J. Climate, 18, 4344-4354, https:// doi.org/10.1175/JCLI3518.1.

Goussard, J. J., and M. Ducrocq, 2014: West African coastal area: Challenges and outlook. The Land/Ocean Interactions in the Coastal Zone of West and Central Africa, S. Diop, J. P. Barusseau, and C. Descamps, Eds., Estuaries of the World, Springer, 9-21, https://doi.org/10.1007/978-3-319-06388-1_2.

Gumbel, E. J., 1935: Les valeurs extrêmes des distributions statistiques (Extreme values of statistical distributions). Ann. Inst. Henri Poincaré, 5,115-158.

Haerter, J. O., S. Hagemann, C. Moseley, and C. Piani, 2011: Climate model bias correction and the role of timescales. 
Hydrol. Earth Syst. Sci., 15, 1065-1079, https://doi.org/ 10.5194/hess-15-1065-2011.

Hawkins, E., and R. Sutton, 2009: The potential to narrow uncertainty in regional climate predictions. Bull. Amer. Meteor. Soc., 90, 1095-1108, https://doi.org/10.1175/2009BAMS2607.1.

Hay, L. E., and M. P. Clark, 2003: Use of statistically and dynamically downscaled atmospheric model output for hydrologic simulations in three mountainous basins in the western United States. J. Hydrol., 282, 56-75, https://doi.org/10.1016/S00221694(03)00252-X.

— R. J. L. Wilby, and G. H. Leavesley, 2000: A comparison of delta change and downscaled GCM scenarios for three mountainous basins in the United States. J. Amer. Water Resour. Assoc., 36, 387-397, https://doi.org/10.1111/j.17521688.2000.tb04276.x.

Hemer, M. A., and C. E. Trenham, 2016: Evaluation of a CMIP5 derived dynamical global wind wave climate model ensemble. Ocean Modell., 103, 190-203, https://doi.org/10.1016/ j.ocemod.2015.10.009.

— X. X. L. Wang, J. A. Church, and V. R. Swail, 2010: Modeling proposal: Coordinated global ocean wave projections. Bull. Amer. Meteor. Soc., 91, 451-454, https://doi.org/10.1175/ 2009BAMS2951.1.

- — — - R. Weisse, and V. R. Swail, 2012: Advancing windwaves climate science: The COWCLIP Project. Bull. Amer. Meteor. Soc., 93, 791-796, https://doi.org/10.1175/BAMS-D11-00184.1.

_ , Y. Fan, N. Mori, A. Semedo, and X. Wang, 2013a: Projected changes in wave climate from a multi-model ensemble. Nat. Climate Change, 3, 471-476, https://doi.org/10.1038/nclimate1791.

_, J. Katzfey, and C. E. Trenham, 2013b: Global dynamical projections of surface ocean wave climate for a future high greenhouse gas emission scenario. Ocean Modell., 70, 221245, https://doi.org/10.1016/j.ocemod.2012.09.008.

Hersbach, H., and Coauthors, 2020: The ERA5 global reanalysis. Quart. J. Roy. Meteor. Soc., 2020,1-51, https://doi.org/10.1002/ QJ.3803.

Högström, U., A. Smedman, E. Sahleé, W. M. Drennan, K. K. Kahma, H. Pettersson, and F. Zhang, 2009: The atmospheric boundary layer during swell: A field study and interpretation of the turbulent kinetic energy budget for high wave ages. J. Atmos. Sci., 66, 2764-2779, https://doi.org/10.1175/2009JAS2973.1.

$\longrightarrow,-$, A. Semedo, and A. Rutgersson, 2011: Comments on "A global climatology of wind-wave interaction." J. Phys. Oceanogr., 41, 1811-1813, https://doi.org/10.1175/JPO-D-10-05015.1.

Holthuijsen, L. H., 2008: Waves in Oceanic and Coastal Waters. Cambridge University Press, 387pp.

IPCC, 2014: Climate Change 2014: Mitigation of Climate Change. Cambridge University Press, 1465 pp., https://www.ipcc.ch/ site/assets/uploads/2018/02/ipcc_wg3_ar5_full.pdf.

Knutti, R., and J. Sedláček, 2013: Robustness and uncertainties in the new CMIP5 climate model projections. Nat. Climate Change, 3, 369-373, https://doi.org/10.1038/nclimate1716.

Łabuz, T. A., 2015: Environmental impacts-Coastal erosion and coastline changes. Second Assessment of Climate Change for the Baltic Sea Basin, The BACC II Author Team, Ed., Regional Climate Studies, Springer, 381-396, https://doi.org/ 10.1007/978-3-319-16006-1_20.

Lemos, G., A. Semedo, M. Dobrynin, A. Behrens, J. Staneva, J.-R Bidlot, and P. Miranda, 2019: Mid-twenty-first century global wave climate projections: Results from a dynamic CMIP5 based ensemble. Global Planet. Change, 172, 69-87, https:// doi.org/10.1016/j.gloplacha.2018.09.011.
—, M. Menendez, A. Semedo, P. Camus, M. Hemer, M. Dobrynin, and P. Miranda, 2020: On the need of bias correction methods for wave climate projections. Global Planet. Change, 186, 103109, https://doi.org/10.1016/j.gloplacha.2019.103109.

Mínguez, R., A. Espejo, A. Tomás, F. J. Méndez, and I. J. Losada, 2011: Directional calibration of wave reanalysis databases using instrumental data. J. Atmos. Oceanic Technol., 28, 14661485, https://doi.org/10.1175/JTECH-D-11-00008.1.

Mori, N., T. Yasuda, H. Mase, T. Tom, and Y. Oku, 2010: Projections of extreme wave climate change under global warming. Hydrol. Res. Lett., 4, 15-19, https://doi.org/10.3178/ hrl.4.15.

Morim, J., and Coauthors, 2019: Robustness and uncertainties in global multivariate wind-wave climate projections. Nat. Climate Change, 9, 711-718, https://doi.org/10.1038/s41558019-0542-5.

NGDC, 2006: 2-minute Gridded Global Relief Data (ETOPO2) v2. NOAA National Geophysical Data Center, accessed 7 December 2019, https://doi.org/10.7289/V5J1012Q.

Perkins, S. E., A. J. Pitman, N. J. Holbrook, and J. McAneney, 2007: Evaluation of the AR4 climate models simulated daily maximum temperature, minimum temperature, and precipitation over Australia using probability density functions. J. Climate, 20, 4356-4376, https://doi.org/10.1175/JCLI4253.1.

Rauser, F., V. Schemann, and S. Sonntag, 2015: Sustainable earlycareer networks. Nat. Geosci., 8, 745-746, https://doi.org/ 10.1038/ngeo2541.

Rocheta, E., J. P. Evans, and A. Sharma, 2017: Can bias correction of regional climate model lateral boundary conditions improve low-frequency rainfall variability? J. Climate, 30, 9785-9806, https://doi.org/10.1175/JCLI-D-16-0654.1.

Rutgersson, A., Ø. Saetra, A. Semedo, B. Carlson, and R. Kumar, 2010: Impact of surface waves in a regional climate model. Meteor. Z., 19, 247-257, https://doi.org/10.1127/0941-2948/ 2010/0456.

Saha, S., and Coauthors, 2010: The NCEP Climate Forecast System Reanalysis. Bull. Amer. Meteor. Soc., 91, 1015-1057, https:// doi.org/10.1175/2010BAMS3001.1.

Semedo, A., 2010: Atmosphere-ocean interactions in swell dominated wave fields. Ph.D. thesis, Uppsala University, 53 pp.

, Ø. Sætra, A. Rutgersson, K. K. Kahma, and H. Pettersson, 2009: Wave induced wind in the marine boundary layer. J. Atmos. Sci., 66, 2256-2271, https://doi.org/10.1175/2009JAS3018.1.

, K. Sušelj, A. Rutgersson, and A. Sterl, 2011: A global view on the wind sea and swell climate and variability from EERA-40. J. Climate, 24, 1461-1479, https://doi.org/10.1175/ 2010JCLI3718.1.

, R. Behrens, A. Sterl, L. Bengtsson, and H. Günther, 2013: Projection of global wave climate change toward the end of the twenty-first century. J. Climate, 26, 8269-8288, https:// doi.org/10.1175/JCLI-D-12-00658.1. , and Coauthors, 2018: CMIP5-derived single-forcing, singlemodel, and single-scenario wind-wave climate ensemble: Configuration and performance evaluation. J. Mar. Sci. Eng., 6, 90, https://doi.org/10.3390/JMSE6030090.

Soares, P., and R. Cardoso, 2018: A simple method to assess the added value using high-resolution climate distributions: Application to the EURO-CORDEX daily precipitation. Int. J. Climatol., 38, 1484-1498, https://doi.org/10.1002/joc.5261.

Stopa, J. E., A. Semedo, M. Dobrynin, A. Behrens, J. Staneva, and G. Lemos, 2019: A sampling technique to compare climate simulations with sparse satellite observations: Performance evaluation of a CMIP5 EC-Earth forced dynamical wave 
climate ensemble with altimeter observations. Ocean Modell., 134, 18-29, https://doi.org/10.1016/j.ocemod.2018.12.002.

Sullivan, P. P., J. B. Edson, T. Hristov, and J. C. McWilliams, 2008: Large-eddy simulations and observations of atmospheric marine boundary layers above nonequilibrium surface waves. J. Atmos. Sci., 65, 1225-1245, https://doi.org/10.1175/2007JAS2427.1.

Terink, W., R. T. W. L. Hurkmans, P. J. J. F. Torfs, and R. Uijlenhoet, 2009: Bias correction of temperature and precipitation data for regional climate model application to the Rhine basin. Hydrol. Earth Syst. Sci. Discuss., 6, 5377-5413, https://doi.org/10.5194/hessd-6-5377-2009.

Tuomi, L., K. Kahma, and H. Pettersson, 2011: Wave hindcast statistics in the seasonally ice-covered Baltic Sea. Boreal Environ. Res., 16, 451-472.

von Storch, H., and F. W. Zwiers, 1999: Statistical Analysis in Climate Research. Cambridge University Press, 484 pp.
Wang, X. L., V. R. Swail, and A. Cox, 2010: Dynamical versus statistical downscaling methods for ocean wave heights. Int. J. Climatol., 30, 317-332, https://doi.org/10.1002/joc.1899.

Wilks, D. S., 1995: Statistical Methods in the Atmospheric Sciences: An Introduction. Academic Press, 467 pp.

Wood, A. W., L. R. Leung, V. Sridhar, and D. P. Lettenmaier, 2004: Hydrological implications of dynamical and statistical approaches to downscaling climate model outputs. Climatic Change, 62, 189-216, https://doi.org/10.1023/B:CLIM.0000013685.99609.9e.

Young, I. R., 1999: Seasonal variability of the global ocean wind and wave climate. Int. J. Climatol., 19, 931-950, https://doi.org/ 10.1002/(SICI)1097-0088(199907)19:9<931::AID-JOC412> 3.0.CO;2-O.

— S. Zieger, and V. Babanin, 2011: Global trends in wind speed and wave height. Science, 332, 451-455, https://doi.org/ 10.1126/science.1197219. 